
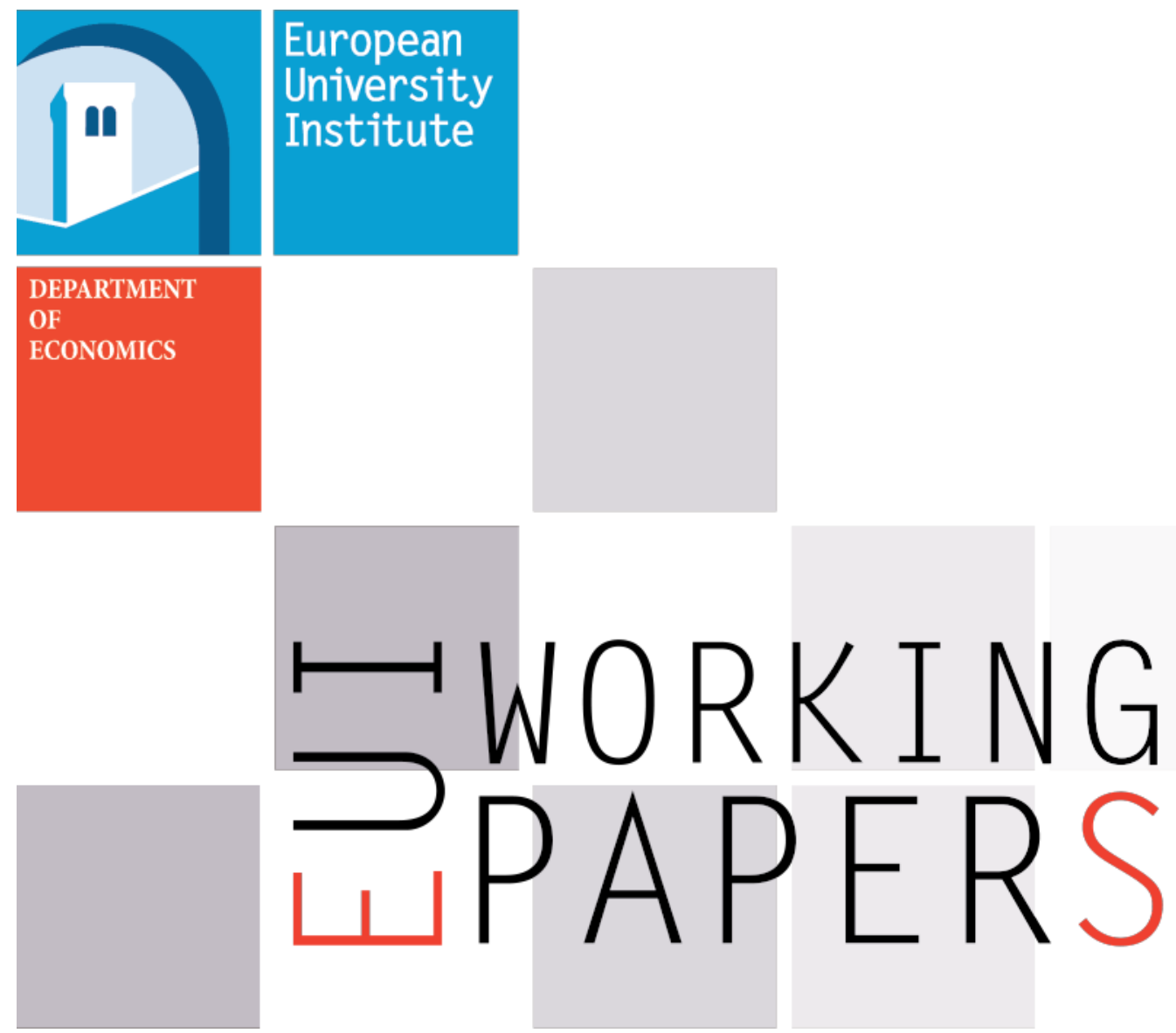

ECO 2016/02

Department of Economics

The Silent Success of Customs Unions

Hinnerk Gnutzmann and Arevik Gnutzmann-Mkrtchyan 

European University Institute

Department of Economics

\section{The Silent Success of Customs Unions}

Hinnerk Gnutzmann and Arevik Gnutzmann-Mkrtchyan

EUI Working Paper ECO 2016/02 
This text may be downloaded for personal research purposes only. Any additional reproduction for other purposes, whether in hard copy or electronically, requires the consent of the author(s), editor(s). If cited or quoted, reference should be made to the full name of the author(s), editor(s), the title, the working paper or other series, the year, and the publisher.

ISSN 1725-6704

(C) Hinnerk Gnutzmann, Arevik Gnutzmann-Mkrtchyan, 2016

Printed in Italy

European University Institute

Badia Fiesolana

I - 50014 San Domenico di Fiesole (FI)

Italy

www.eui.eu

cadmus.eui.eu 


\title{
The Silent Success of Customs Unions
}

\author{
Hinnerk Gnutzmann ${ }^{\mathrm{a}, *}$, Arevik Gnutzmann-Mkrtchyan ${ }^{\mathrm{b}}$ \\ ${ }^{a}$ Universita Cattolica del Sacro Cuore and European University Institute \\ ${ }^{b}$ Leibniz University Hannover and European University Institute
}

\begin{abstract}
While "mega FTAs" and WTO-driven efforts at multilateral liberalisation dominate the agenda, customs unions $(\mathrm{CU})$ are the silent success story of regional integration. Throughout the world, CUs have been superseding earlier FTAs, as new unions were formed or old ones expanded. Due to problems of measurement, this fact appears to have gone largely unnoticed so far. We show that the proliferation of CUs is driven by national social welfare considerations: even allowing for lobbying, CUs lead to higher social welfare than any other bilateral trade agreement. Thus, even the most ambitious mega FTAs eventually turn into "mega CUs".
\end{abstract}

Keywords: customs unions; political viability; member welfare

JEL: F12, F13, F14

\footnotetext{
${ }^{*}$ Corresponding author. We thank Luigi Filippini, Piero Gottardi and Natalya Volchkova who followed and supported the paper throughout; seminar audiences at the EUI in Florence, New Economic School in Moscow and Catholic University of Milan and Kiel Institute of World Economics, and conference participants at ETSG 2012 in Leuven, RIEF 2012 in Milan and EEA 2013 in Gothenburg for their helpful comments. Discussions with Christian Henn, Emanuel Ornelas, Kamal Saggi, Bernard Hoekman, Martin Gassebner, David Tarr and Gerald Willmann substantially improved the paper.

Email addresses: hinnerk.gnutzmann@unicatt.it (Hinnerk Gnutzmann), mkrtchyan@mak. uni-hannover.de (Arevik Gnutzmann-Mkrtchyan)
} 


\section{Introduction}

Customs unions (CUs), regional trade agreements (RTAs) committing members to zero internal tariffs and a common external tariff (CET), are the silent success of regional integration in the past two decades ${ }^{1}$. Much of this success is by superseding a complex web of earlier agreements in many regions of the world; due to problems of measurement, discussed below, this story has so far been largely overlooked. Since CUs have more protectionist tariff policies than FTAs when tariffs are set endogenously (Ornelas, 2007), this has potentially profound welfare consequences. However, until now, the issue has remained an "open question" (Freund and Ornelas, 2010, p. 25). The present paper seeks to fill this void, through a comprehensive social welfare and political economy analysis of trade agreements that encompasses CUs.

Customs unions have rapidly proliferated from Latin America through Europe to Eurasia in past decades. This success has been driven by comparatively few, but important agreements, which have often replaced earlier free trade agreements. Since much of the literature simply counts the number of trade agreements to gauge their relative importance ${ }^{2}$, this development has been largely overlooked in

\footnotetext{
${ }^{1}$ The trade agreements literature frequently uses terms " regional trade agreement" (RTA) and "preferential trade agreement" (PTA) in an interchangeable manner. We will follow the WTO terminology where PTAs refer to the unilateral trade preferences. While the term RTA is reserved for reciprocal trade agreements. See https://www.wto.org/english/tratop_e/ region_e/rta_pta_e.htm.

${ }^{2}$ See Crawford and Fiorentino (2005), WTO (2011), Baier and Bergstrand (2007), Dür et al. (2014), Lake (2014), Lake et al. (2014), Missios et al. (2014), Baldwin and Jaimovich (2012). The last paper, interestingly, finds a strong theoretical motivation for the contagion effect of CUs via enlargement but then dismisses the finding observing that the CUs are rare in numbers. At the same time, their main empirical analysis involves country dyads but, unfortunately, pool CUs and FTAs. When comparing the dyads, the number of pairs that are in FTA vs CU is actually very close (e.g., Figure 1 in Freund and Ornelas (2010)).
} 
the literature ${ }^{3}$. While in the past, ambitious CU projects were at times notified to the WTO but without implementation following suit, this situation has reversed since the early 1990s. In fact, many CUs saw rapid expansion - notably in Europe - while others were implemented for the first time. Hence, it is important for research to understand not only why CUs are so strong in political viability, but also what the welfare consequences are of the expansion of this type of trade agreement.

Building on the canonical regionalism model with imperfect competition ${ }^{4}$, we show that CUs are more politically viable than FTAs, and FTAs can be turned into CUs. Thus, our analysis suggests that FTAs are not likely to lead to everstronger liberalisation towards third countries (Goyal and Joshi, 2006) (possibly after a brief period of higher tariffs as in Bagwell and Staiger (1997)), but instead formation of blocs of CUs with higher external tariffs. But we also show that customs unions can be an engine for development: even when governments are favouring firm interests over welfare, social welfare in member states is highest under CU as long as trade with the rest of the world does not cease. This contrasts with earlier results, such as in Cadot et al. (1999), which found FTAs to welfaredominate CUs. Theoretically, our contribution is in considering GATT/WTO most favoured nation (MFN) regime, FTA and CU in a unified framework that allows for the political bias in the government's decisions.

In contrast to earlier papers, we allow for lobbying of governments by domestic firms and endogenous tariff setting as in Ornelas (2005a). We show that a cus-

\footnotetext{
${ }^{3}$ Relating to problems of measurement in trade, see also Lavallée and Vicard (2013)

${ }^{4}$ See Baksi (2014), Krishna (1998), Freund (2000), Ornelas (2005a), Saggi (2006), Goyal and Joshi (2006), Ornelas (2007) and Zissimos (2011).
} 
toms union maximizes the political objective of each potential member government among all possible bilateral agreements, including those not feasible under GATT principles. While it is well known that formation of a free trade agreement is sometimes politically viable when countries previously engaged trade under MFN (Ornelas, 2005a,b), our analysis shows them to be inefficient agreements - they lead to tariffs that are "too low", both from a political and member social welfare perspective. Turning an FTA into a CU is therefore politically viable, but leads to excessively high external tariffs from a welfare perspective if the government is biased. However, there are limits to the adverse effects of customs unions: as long as trade with the rest of the world remains positive, member social welfare under a CU is higher than under FTA.

Comparing our work with the earlier theoretical findings, most the closely related is Ornelas (2007). The paper compares the MFN and CU regimes. The MFN provides flexibility in policy setting by allowing to raise duties from all trading partners, thus making the marginal cost of a tariff relatively low. Instead, in the $\mathrm{CU}$ the countries are restricted to raising duties only from the rest of the world. On the flip side the CU brings gains from coordination. Thus, the comparison is not straightforward as the set of feasible tariffs of the two regimes is not the same. Ornelas (2007) was the first to demonstrate that the gains from coordination of the CU prevail over the losses in flexibility in tariff setting. This was shown for the case of benevolent government and monopolies in the members of the CU. However the paper left open whether the results are robust to more general production structure in member countries, and to the problem of the political bias of the government. The latter problem is of particular interest because once the government objective diverts from welfare maximisation, the questions 
of viability of an agreement and its welfare properties do not go hand in hand. Thus, by considering the unified framework with all three agreements and with a politically motivated government, we are able to set straight the emerging trade regime and discover some new insights about the relationship between the social welfare and the viability of different regimes.

We contribute to the literature in three ways. First, we show empirically how strongly customs unions have proliferated in recent years, often replacing earlier FTA relationships. Second, a number of very interesting theoretical studies have emphasized benign consequences of free trade agreements, showing that even tariffs on non-members may endogenously fall (Richardson, 1993), that politically viable FTAs must be globally welfare improving (Ornelas, 2005a) and can pave the path towards multilateral liberalization (Goyal and Joshi, 2006; Saggi and Yildiz, 2010). We show that it is politically feasible to turn any bilateral trade relation, including FTA and MFN, into CUs, and that the stricter equilibrium tariff policy under CU quite profoundly alters welfare conclusions. Finally, we provide a sufficient - and easily observable - condition for a customs union to improve social welfare of members in a political economy setting: as long as trade with non-member states remains positive, CU improves member social welfare.

We proceed by giving more evidence on the "silent success" of CUs in section 2. Section 3 then introduces the model, and solves the market outcome and tariff setting changes. Section 4 then turns to central results on political viability and welfare. Subsequently, the next section develops extensions regarding border effects and asymmetric production structures. Finally, section 6 concludes. 


\section{Silent Success: Customs Unions replace FTAs}

Customs unions have rapidly proliferated around the globe in past decades; however, this success has been largely obscured for two reasons. First, a large number of free trade agreements have been de facto superseded by CUs - a fact not noted in the datasets, and hence frequently overlooked. The EU Eastern Enlargement is a case in point, when the Nice Treaty superseded 62 earlier FTAs with the stroke of a pen. Second, a number of large CUs have in the past been notified to the WTO, without implementation following suit (such as the African Economic Community, created with an incredible 51 members in 1991). At times, this has led to doubt whether the data on customs union agreements are reliable after all. In this section, we address both problems: first, using a simple algorithm, we identify the extent of FTA supersesion in recent decades. Second, we verify the implementation status of each CU from external sources, presenting - to our knowledge - the first dataset of implemented CUs, together with the implementation year of the common external tariff.

Data: Our analysis builds on the Design of Trade Agreements (DESTA) database by Dür et al. (2014), in the version of 18 June 2015. This dataset contains both the agreements that were notified to the WTO, including their WTO depth status, and agreements that were not notified to the $\mathrm{WTO}^{5}$. Moreover, for each agreement, a measure of coverage depth is provided.

\footnotetext{
${ }^{5}$ Scott Baier and Jeffrey Bergstrand also provide a dataset of regional trade agreements (RTAs) https://www3.nd.edu/ jbergstr/. One strength of their dataset that could be helpful for indepth analysis of particular agreements is linking the agreements with the original texts. However their dataset has lower coverage than DESTA and goes only until 2005.
} 
Customs unions superseding FTAs: We refer to an agreement as superseded when a new, deeper, agreement is created where all members are included. We need this procedure to determine the superseded agreements: when a new agreement that makes an existing one redundant is signed, the redundant weaker agreement remains technically in force in datasets. Specifically, our algorithm assigns trade agreement $y$ as superseding trade agreement $x$ if and only if all of the following conditions are met: the agreement $y$ contains at least all members of agreement $x$, it is of greater depth 6 than $x$ and agreement $x$ precedes $y$ in time ${ }^{7}$.

Figure 1 presents the results from this analysis. Importantly, the algorithm allows us to identify several important episodes of "FTA destruction" when small FTAs are consolidated into a larger agreement or mature into a customs union. Most notably, when the treaty of Nice came into force in 2003, 59 earlier free trade agreements were superseded. Since the earlier FTAs were largely bilateral, the large number of superseded agreements is not surprising. However, it highlights the need to go beyond agreement counting in order to gauge the importance of different types of trade agreements. Other episodes of FTA destruction via FTAs maturing into CUs are related to the formation of Mercosur and the Eurasian Customs Union. Moreover, in 1997, the Greater Arab Free Trade Agreement consolidated 13 previously separate bilateral treaties into one.

Implementation of $C U$ Agreements: For each CU included in the DESTA dataset, we looked for evidence of implementation of a common external tariff. The con-

\footnotetext{
${ }^{6}$ Measured by the TypeDepth variable in the DESTA dataset

${ }^{7} \mathrm{~A}$ complete dataset of superseded agreements is available as an online appendix
} 
Figure 1: Trade Agreements Created and Superseded: 1980-2014

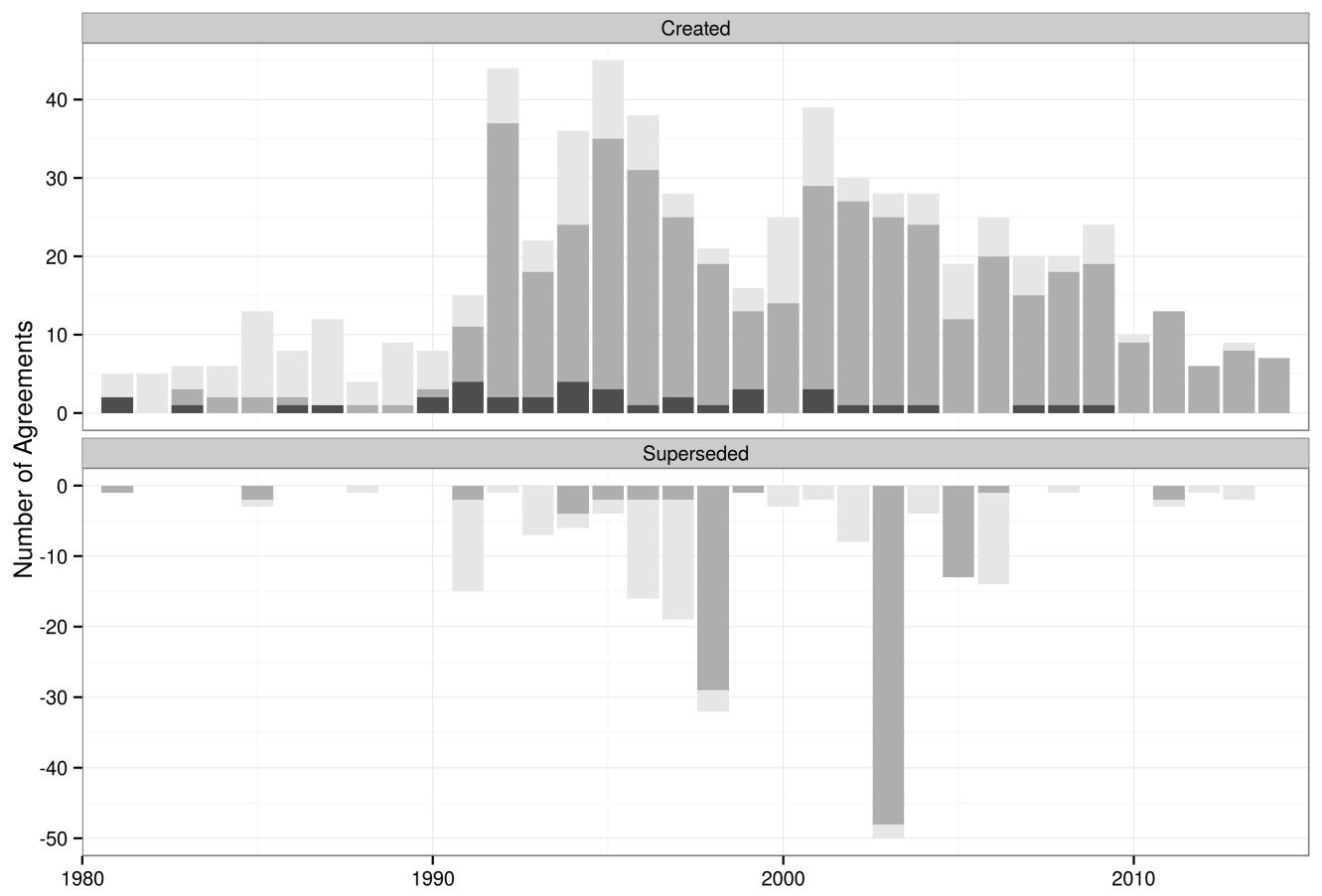

Note: The depth of the colour corresponds to the depth of the agreement. Agreements in light grey represent partial scope agreements, in darker grey - FTAs and in black CUs. An agreement is defined as "superseding" an earlier one if it contains all members of the previous agreement has a greater depth. All superseded FTAs are superseded by CUs while the PSAs can be superseded both by FTA and CU. 
Figure 2: Silent Success of Customs Unions: 1992-2014

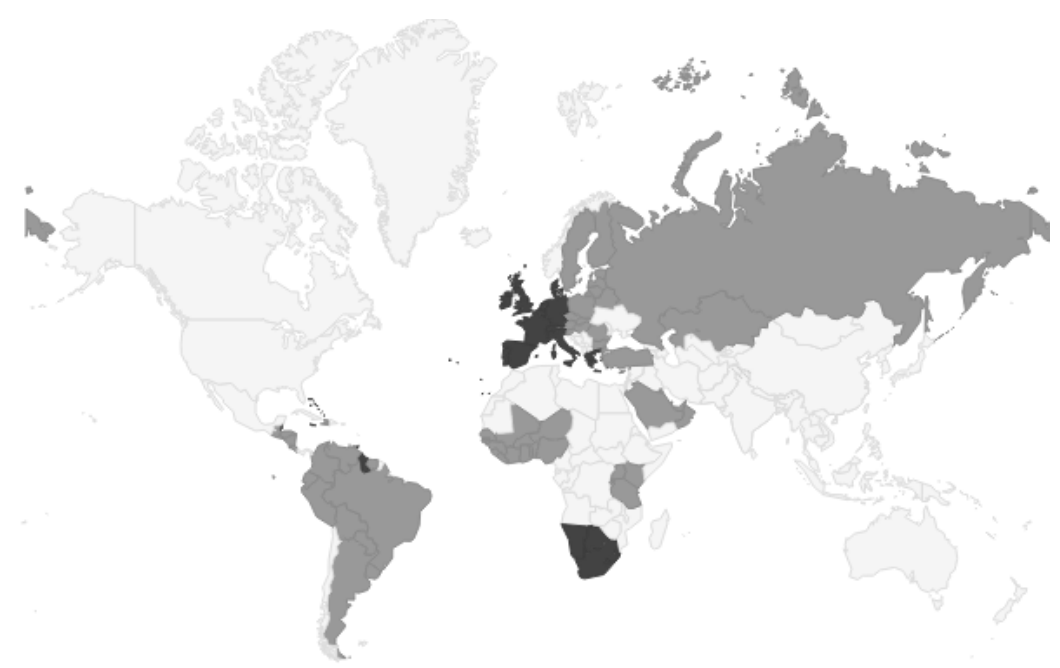

Note: Countries marked in dark grey of a customs union by 1992; countries in light grey joined a customs union between 1992 and 2014. We use 1992 as the base year, because this is the first year where the newly independent states of the former Soviet Union appear in the datasets; 2014 is the last year for which data are available. 
firmed implemented CUs are presented in table 1, together with the references confirming CET implementation and the year when a CET was first applied.

Next, we conducted a further selection among the existing customs unions. The trade agreement dataset sometimes presents as completely different agreements the enlargements of existing agreements. For example, EC-Turkey CU, EC-San Marino and EU enlargements are all, in fact, enlargements of the European Union Customs Union, rather than unrelated agreements as RTA datasets would suggest. Similarly, the CU of Russia, Belarus and Kazakhstan and Eurasian Economic Community are related to one trading system. Again, a similar problem could be present in the case of FTAs but our analysis takes at face value each FTA while checking one by one the customs unions. This concern that several agreements can actually be related to one trading system also speaks for the need of focusing on agreement profiles of countries or dyadic trade relationships rather than counting the number of agreements in order to analyse the regional trading systems.

Applying this stringent benchmark in selecting the CUs further highlights the growing importance of CUs in the world trading systems. We could verify implementation of the CET for a total of 9 different non-intersecting customs unions involving 76 countries. Each separate customs union is highlighted in gray while various agreement that comprise it are listed below. In the case of European Union Customs Union only the most important agreements are listed. We provide the name of the agreement and ID number as it enters the DESTA database.

Table 1 presents the number of member countries of each customs union in 1992 and 2012. All CUs were either formed since 1992 or showed a growth in membership between 1992 and 2012, except for Switzerland-Liechtenstein and the Southern Africa Customs Union, the two oldest customs unions still in force. The 
number of countries that are members of a customs union more than doubled from 34 to 76 countries in the recent two decades. Table 3 provides the list of members of each verified customs union in 1992 and 2012.

Additionally, Table 1 presents the year of ratification of each relevant agreement that is related to each separate customs union and the year of implementation of the common external tariff. The last column lists the sources we used to identify the implementation of the CET. 
Table 1: Worldwide list of CUs with Implementation of Common External Tariff

\begin{tabular}{|c|c|c|c|c|c|c|}
\hline \multirow[b]{2}{*}{ No } & \multirow[b]{2}{*}{ Agreement Name } & \multicolumn{2}{|c|}{ Year } & \multicolumn{2}{|c|}{ \# Members } & \multirow[b]{2}{*}{ Source } \\
\hline & & Ratif. & Impl. & 1992 & 2014 & \\
\hline & Andean Community & 1987 & 1995 & 0 & 4 & Gomez (2014) \\
\hline 27 & Quito Protocol & 1987 & & & & \\
\hline 23 & Trujillo Protocol & 1996 & & & & \\
\hline \multirow[t]{2}{*}{694} & Sucre Protocol & 1997 & & & & \\
\hline & Caribbean Community (CARICOM) & 1973 & 1973 & 13 & 15 & CARICOM (2011), \\
\hline 171 & Caribbean Community(CARICOM) & 1973 & & & & Sadikov (2013) \\
\hline 177 & Caribbean Community(CARICOM) & 2001 & & & & \\
\hline \multirow[t]{2}{*}{638} & Organisation of Eastern Caribbean States(OECS) & 1981 & & & & \\
\hline & East African Community (EAC) & 1999 & 2005 & 0 & 5 & EAC (2015) \\
\hline \multirow[t]{2}{*}{787} & East African Community(EAC) & 1999 & & & & \\
\hline & Eurasian Customs Union & 2009 & 2010 & 0 & 3 & Mkrtchyan (2013), EAEU (2015) \\
\hline 108 & Belarus Russia & 1995 & & & & \\
\hline 435 & Eurasian Economic Community & 1995 & & & & \\
\hline \multirow[t]{2}{*}{104} & Belarus Kazakhstan Russia & 2009 & & & & \\
\hline & European Union Customs Union ${ }^{1}$ & 1957 & 1958 & 15 & 31 & EC (2015a), \\
\hline 293 & $\mathrm{EC}$ & 1957 & 1958 & & & $\mathrm{EC}(2015 \mathrm{~b})$ \\
\hline 28 & Andorra EC & 1990 & & & & \\
\hline 341 & EC San Marino & 1991 & & & & \\
\hline 327 & EC Maastricht & 1992 & & & & $\mathrm{EC}(2015 \mathrm{c})$ \\
\hline 355 & EC Turkey & 1995 & & & & \\
\hline \multirow[t]{2}{*}{335} & EC Nice & 2001 & & & & EUR-Lex (2015) \\
\hline & Gulf Cooperation Council (GCC) & 2001 & 2003 & 0 & 6 & Fasano-Filho (2003) \\
\hline 473 & Gulf Cooperation Council (GCC) & 1981 & & & & \\
\hline 474 & Gulf Cooperation Council (GCC) & 2001 & & & & \\
\hline \multirow{3}{*}{604} & MERCOSUR & 1991 & 1995 & 0 & 5 & Olarreaga and Soloaga (1998) \\
\hline & MERCOSUR & 1991 & & & & \\
\hline & Southern Africa Customs Union & 1910 & 1970 & 5 & 5 & McCarthy (2003), \\
\hline- & Southern Africa Customs Union & 1910 & & & & SACU (2015) \\
\hline 669 & Southern Africa Customs Union & 1969 & & & & \\
\hline \multirow[t]{2}{*}{670} & Southern Africa Customs Union & 2000 & & & & \\
\hline & Central American Common Market & & & 0 & 5 & Bronchi and Chua (2005), \\
\hline 186 & Central American Common Market (CACM) & 1960 & 1997 & & & Bulmer-Thomas (1998) \\
\hline 714 & Protocol of Guatemala & 1993 & & & & \\
\hline \multirow[t]{2}{*}{790} & El Salvador Guatemala & 2000 & & & & \\
\hline & ECOWAS $^{2}$ & 1966 & 2013 & 0 & 15 & Von Uexkull and Shui (2014), \\
\hline 726 & UDEAO & 1966 & & & & \\
\hline 780 & West African Econonomic Community (CEAO) & 1973 & & & & \\
\hline 688 & West African Economic and Monetary Union & 1994 & & & & Goretti and Weisfeld (2008) \\
\hline 366 & Economic Community Of West African States & 1975 & & & & \\
\hline 367 & Economic Community Of West African States & 1993 & & & & \\
\hline 600 & Mano River Union & 1973 & & & & \\
\hline- & Switzerland-Liechtenstein & 1923 & 1923 & 2 & 2 & WTO (2000) \\
\hline Total & & & & 35 & 96 & \\
\hline
\end{tabular}

Notes: Related Document Number and Name correspond to the agreements listed in the DESTA database which is itself based on the WTO RTA database.

1 There are more agreements related to the European Union Customs Union in the DESTA database listed as independent RTAs. Only several most important ones are included here for economy of space. The full list of associated agreements for the EUCU and other CUs can be found in the online appendix.

2 Members of ECOWAS participated in regional integration in smaller groups with intersecting membership as well, - West African Monetary Zone and West African Economic and Monetary Union (WAEMU), which became customs union prior to ECOWAS as WAEMU adopted a CET in 2000. Additionally, 4 ECOWAS members are also members of the Mano River Union (MRU) created in 1973; MRU becamse a CU with a CET first in 1977, but shortly after became ineffective until the revival in 2008 (World Bank, 2013). Alva and Behar (2009) discuss the complex structure of African RTAs and the levels of integration 


\section{Silent success: theory}

This section develops a standard model of regional trading blocs where governments choose between a Most Favoured Nation regime (no regional agreement), a Free Trade Agreement and a Customs Union. Our goal is to extend this model where either of three regimes can arise endogenously to a more general industrial competition structure and allow for a politically motivated government. We find that this standard model is predicting the spread of customs unions: it is chosen by the governments over a more protectionist regime (MFN) and more liberal regime (FTA). Note, this happens as government may not be benevolent but driven by contributions from firms and, as we show, for almost all parameter values firms would be better off under MFN. This is due to the balance brought by customs unions: the more the government would be driven by firm interest that would prefer MFN and be more protectionist, the more the consumers would lose, thus making the CU a preferred regime by the government. The extentions section modifies the model in several ways, including introduction of asymmetries of production structures, where the result still holds. This robustness of customs unions as a trade regime choice in the model helps to develop an intuition for the empirical success we argued for above.

Our set-up closely follows the standard regionalism model under imperfect competition with segmented markets as in Brander and Krugman (1983). Further, in Ornelas (2005a), governments take an active role - endogenously setting their external tariff policy and choosing preferential trade agreements to optimally meet their objectives. The model contains three stages: first, governments may choose to ratify an RTA. Second, government sets the optimal tariffs, taking the RTA 
as given. Finally, market outcomes unfold through the actions of firms and constrained by the tariff policy in place. The main departure from previous papers is that we model customs unions as a potential trade agreement in addition to FTA and MFN (i.e., absence of agreement). Thus, our analysis covers all "exceptions" to the MFN principle of GATT XXIV in a unified setting.

Countries and Markets: Our world economy consists of two potential partner countries in a trade agreement - indexed $i$ and $j$ respectively - and the rest of the world, $k$. Each country has $n$ firms producing a homogeneous good under constant returns to scale with marginal cost normalised to zero (called "imperfectly competitive good"). Markets are nationally segmented and have Cournot competition; thus, each firm from country $l$ sets a vector of quantities $\left\{q_{h l}\right\}$ determining its output in a given market $h$ for all $h, l=i, j, k^{8}$. Furthermore, there is one numeraire good produced competitively.

There is a representative consumer in each country, whose utility is linear in the competitive good and quadratic in the imperfectly competitive good. Hence, the utility function of a consumer in country $h$ is given by:

$u\left(Q_{h}\right)=\Gamma Q_{h}-\left(Q_{h}^{2} / 2\right)$, where $Q_{h}=\sum_{l \in\{i, j, k\}} q_{h l}$ is the total output available in the country.

Welfare and Government Objective: We define the social welfare, $W$, in a standard manner: it is the sum of consumer surplus, tariff revenue and producers

\footnotetext{
${ }^{8}$ first letter in the subscript will always denote the market and the second - the origin.
} 
profits:

$$
W_{h}\left(\boldsymbol{t}_{h} ; \boldsymbol{t}_{-h}\right)=W_{h}\left(\boldsymbol{t}_{h}\right)+(1+\alpha) \Pi_{h}\left(\boldsymbol{t}_{h} ; \boldsymbol{t}_{-h}\right)
$$

where $C S_{h}$ and $\Pi_{h}$ are consumer and producer surplus respectively, and $T R_{h}$ denotes the tariff revenue.

Government preferences are defined as in Grossman and Helpman (1994), i.e. the government values increases in national welfare, but gives an extra bias measured by $\alpha$ - to "contributions" received from industry. This gives rise to a government objective function as follows:

$$
G_{h}\left(\boldsymbol{t}_{h} ; \boldsymbol{t}_{-h}\right)=C S_{h}\left(\boldsymbol{t}_{h} ; \boldsymbol{t}_{-h}\right)+T R_{h}\left(\boldsymbol{t}_{h}\right)+(1+\alpha) \Pi_{h}\left(\boldsymbol{t}_{h} ; \boldsymbol{t}_{-h}\right)
$$

The parameter $\alpha \geq 0$ represents the political bias, through which producer interests are overweighted when policy is determined. As in Ornelas (2005a), we follow Maggi and Rodriguez-Clare (1998) in deriving the political bias as the set of efficient outcomes of a bargaining game between firms and the government: in the absence of contributions, the government sets the welfare maximising tariff (disagreement point). Firms, whose ownership is concentrated, are willing to compensate the government for deviations from the welfare maximising tariff with an increased contribution. As Ornelas (2005a, section 2.3) shows, the efficient outcomes of this bargaining process satisfy the first-order condition of 2 .

Due to the segmented markets assumption of the model, a government's first order condition for tariff setting does not depend on tariffs of other countries; hence we drop the arguments $\boldsymbol{t}_{-h}$ henceforth to simplify the notation.

The industry profits $\Pi_{h}$ of the firms from $h$ consist of the profits made at home, 
denoted $\Pi_{h h}$ and profits made in a foreign country $l$, denoted as $\Pi_{l h}$.

Trade Agreements and External Tariffs: We model all three permissible bilateral trade regimes under article XXIV. In a customs union (CU), the external tariff is set cooperatively; in practice, an intergovernmental body is often created that determines the external tariff policy. In line with the literature, we assume that the external tariff is chosen to maximise the joint welfare of the partner countries. Two important constraints apply: first, internal tariff barriers must be eliminated as in an FTA. Additionally, the external tariffs imposed by each partner country $\mathrm{i}$ and $\mathrm{j}$ on the rest of the world $\mathrm{k}$ must be equal:

$$
\begin{aligned}
\boldsymbol{t}^{C U}=\underset{\boldsymbol{t}_{i}, \boldsymbol{t}_{j}}{\operatorname{argmax}} & G_{i}(\boldsymbol{t})+G_{j}(\boldsymbol{t}) \\
\text { s.t. } & t_{i j}=0, t_{j i}=0 \\
& t_{i k}=t_{j k}
\end{aligned}
$$

In a free trade area (FTA), the member government is committed to a zero internal tariff with its partner; it remains to impose, non-cooperatively, the politically optimal tariff on firms from country $\mathrm{k} k$. This yields the problem for a country h in an FTA:

$$
\begin{aligned}
\boldsymbol{t}_{h}^{F T A}=\underset{\boldsymbol{t}_{h}}{\operatorname{argmax}} & G_{h}(\boldsymbol{t}) \\
\text { s.t. } & t_{h k}=0, h \in\{i, j\}
\end{aligned}
$$

for each member state.

When a country is not in any trade agreement - so tariffs are set merely according to the most favoured nation principle (MFN) - in the world of our model 
the government country $h$ imposes equal tariffs on both other countries. Hence, each government's problem is

$$
\begin{aligned}
\boldsymbol{t}_{h}^{M F N}=\underset{\boldsymbol{t}_{h}}{\operatorname{argmax}} & G_{h}(\boldsymbol{t}) \\
\text { s.t. } & t_{h l}=t_{h m}, \quad h, l, m \in\{i, j, k\}
\end{aligned}
$$

Ratification and Timing: In the first period ("ratification stage"), countries $i$ and $j$ simultaneously announce a trade agreement they would be willing to enter with the other country, $\phi_{h} \in\{F T A, C U, M F N\}$. If countries make the same announcement, the agreement is implemented; otherwise, MFN prevails. Then follows the "tariff-setting stage", in which the governments or Commission of the customs union determines external tariff so as to maximise the objective functions just described. Finally, firms produce and consumers consume in the "market outcome stage".

Solution Method: Given the sequential, perfect information structure of the game, the solution concept is Subgame Perfect Nash Equilibrium and we proceed by backwards induction. Since solution of the last stage - market outcomes - is standard, we relegate the relevant calculations to the appendix.

In the remaining part for expositional purposes the presenation will be made for the country $i$. 


\subsection{Trade Agreements and Tariff Policy}

It is a "safe bet" that preferential trade agreements profoundly alter the incentives of governments to set external tariffs (Freund and Ornelas, 2010). This tariff channel is the fundamental reason why FTA and CU affect world trade differently. Hence, this section establishes a comparative view of external tariff policy, first comparing the two types of preferential trade agreement, and then a discussion of CU vis-a-vis MFN.

Customs Union vs FTA: In a free trade area, each partner country unilaterally solves problem 4, while a single supranational institution determines the joint external tariff for both members under CU, solving problem 3. While in principle, FTA members could charge different tariffs, it is an equilibrium outcome that their external tariffs are identical; hence one may compare the FTA and CU tariff levels directly:

Lemma 1. External Tariffs: Customs Union vs FTA

1. A free trade agreement imposes a strictly lower external tariff than a customs union, $t_{i k}^{F T A}<t_{i k}^{C U}$

2. The stronger the political bias, the more CU external tariff exceeds FTA

Proof. See Appendix

As Saggi (2006) and Ornelas (2007) emphasise, centralised tariff setting in a customs union leads to consideration of profits arising from cross-border trade; hence, tariffs are higher. While a stronger political bias leads to higher tariffs both under FTA and CU, the effect in a CU is even stronger - because the marginal 
political returns to higher tariffs are larger in CU than FTA. This is due to absence of "leakage", in the terminology of Freund and Ornelas (2010): a higher tariff benefits always also the partner country, and only under CU are those gains internalised in endogenous tariff setting. However Bohara et al. (2004) find some evidence for the tariff complementarity in the formation process of MERCOSUR in Argentina's tariffs - as the average tariff went up to be closer aligned with the Brazilian tariff and the internal tariff was going down, the tariffs in the sectors most affected by the trade diversion saw a decrease.

Estevadeordal et al. (2008) study the impact of the RTAs of 10 Latin American countries on the non-member tariffs. Consistently with theory, they find that moving from an FTA to a CU (cases of MERCOSUR and Andean Community) leads to an increase in the tariffs towards non-members.

Customs Union vs Most Favoured Nation: MFN tariffs are higher than CU ones, but the effects are complex. In an MFN regime, tariff revenue and domestic profits are higher than under CU, calling also for higher tariffs at the margin. On the other hand, consumer surplus is lower, and would call for a lower tariff. In principle, the comparison could thus go either way. In Ornelas (2007), for example, the potential partners each have a single firm while the number of firms in the rest of the world is a parameter. In this environment, the $\mathrm{CU}$ tariff is higher than MFN when the number of firms abroad is sufficiently large and otherwise below. In contrast, the present model has an arbitrary, but symmetric, number of firms in each country, allowing a definitive comparison of the tariffs (we relax the symmetry assumption in section 5.2): 
Lemma 2. External Tariffs: Customs Union vs MFN

i. Under MFN, the external tariff is strictly higher than under customs union: $t_{i k}^{M F N}>t_{i k}^{C U}$

ii. The stronger the political bias, the more the MFN tariff exceeds the $C U$ external tariff

Proof. See Appendix

Magee and Lee (2001) show that the European Economic Community, created from an MFN basis, led to a mild decrease $(0.9 \%)$ in the average tariffs, similar to the theoretical prediction.

\section{Political Viability and Welfare}

Given the political tariffs determined in the previous section, we now study which agreements are politically viable. We show that the Customs Unions dominates all other RTAs in this regard. Hence, the formation of a CU can always occur in equilibrium; however, an example demonstrates that this does not rule the possibility that an FTA may be formed. We next turn a careful welfare analysis and provide the central result: a CU also leads to the highest social welfare in member countries as long as trade with the rest of the world does not cease. This holds in spite of excessively high tariffs due to lobbying. One may thus say that political viability and member welfare go hand in hand.

Political Viability: In the first stage, the potential partner governments simultaneously announce a trade agreement they would be willing to the enter with 
the respective other; if the announcements match, the agreement is implemented; else MFN prevails. Due to political bias, governments take into account not only welfare considerations when proposing an agreement, but also rents that can potentially be obtained from producers. Thus, political viability in our context is a separate concern from social welfare, a point of departure from the models of Ornelas (2007), Saggi et al. (2013) and Yi (1996).

Customs union choice is payoff dominant for the government over any other trade agreement. In other words, a CU not only outperforms FTA and MFN from a government payoff perspective, but those not permitted under GATT/WTO rules (e.g. containing only partial goods coverage or reducing, but not eliminating internal tariffs). This generalisation is a more technical contribution of the following proposition; it suggests that the twin requirements to "eliminate" internal tariffs on "substantially all" trade may not necessarily constrain governments in practice $^{9}$.

Proposition 1. For all values of the political bias, and any number of firms, a customs union yields strictly higher government payoff in each member country than

i. trade under the most favoured nation principle

ii. a free trade agreement

iii. any other possible bilateral agreement, including those ruled out by GATT/WTO

Proof. See Appendix

\footnotetext{
${ }^{9}$ In line with practical experience, cf Mavroidis (2006, 2011).
} 
Most closely related, in Ornelas (2007, proposition 2), a special case of results (i) and (ii) is obtained for social welfare maximising governments and monopoly production in the partner countries. In that framework ${ }^{10}$, the $\mathrm{CU}$ implements the social welfare maximising tariffs; MFN and FTA imply different tariffs, and consequently must lead to lower welfare. In contrast, in a setting with political bias, all regimes are subject to different distortions; as the proposition showed, these distortions do not challenge the government payoff dominance of the customs union.

When comparing FTA and CU regimes, only the external tariff changes since internal tariffs are already eliminated. Here, the advantages of CU from a government perspective are clear: improved coordination not only increases social welfare, but also producer profits; due to political bias, the CU is a fortiori preferred over MFN. In contrast, the comparison between $\mathrm{CU}$ and MFN is more intricate - tariffs change not only with respect to the rest of the world, but also discontinuously with the partner country. As it turns out, from the government's perspective, higher home market profits under MFN do not outweigh the loss of market access to the partner country.

To see why custom unions dominate also other possible trade agreements, the intuition is two-fold. First, tariffs on internal trade are a transfer from producers in the partner country and domestic consumers to the government purse; especially if producer lobbying is politically important. Governments thus want to eliminate internal tariffs - even if they were not forced to do so - when forming an optimal bilateral agreement. In fact, if import subsidies were allowed, they would be called

\footnotetext{
${ }^{10}$ Corresponding to parameters $N=1$ and $\alpha=0$ in our model, for the case when the number of firms in all three countries is equal
} 
for both, to further boost profits and reduce underproduction implied by imperfect competition. Second, due to the symmetry of the model, there is no reason for the partner countries to want to charge different tariffs; hence this constraint is also non-binding. As we show in section 5.2, the result extends to the case of asymmetric production structures.

Since CUs are relatively protectionist, one may be tempted to think that firms necessarily prefer this trade agreement. However, as the following lemma shows, that is not the case: as the number of firms increases over monopoly, firms prefer MFN rather than $\mathrm{CU}$, for that is the trade regime that maximises their profits:

Lemma 3. For any $n>1$ and any level government bias, firms prefer MFN over other trade regimes. In case of monopolies, $n=1$, the firms prefer customs union.

Proof. See appendix

Thus, the industry profits are higher under MFN when the markets are competitive. This result is related to the ability of the government to raise duties from both partners under MFN. While the industry profits are higher in CU in the case of fewer firms, government prefers $\mathrm{CU}$ even when it puts an extra weight on the firms. The happens because the $\mathrm{CU}$, as a more liberal to the MFN regime, delivers higher consumer surplus. As a result, as the government becomes more concerned with the industry profits, the difference in the government payoff under MFN and $\mathrm{CU}$ does not change change monotonically. Interestingly, despite that, we show that for any number of firms and any level of government bias the $\mathrm{CU}$ is preferred by the government to the MFN, even when the MFN would lead to higher industry profits as then the effects of the more liberal regime of the CU dominates. 
The reason is that in the cases where the industry prefers the MFN, the CU brings such an increase in consumer surplus through higher consumption, that this difference combined with endogenous tariff setting (i.e. $\left.d\left(t^{M F N}-t^{C U}\right) / d \alpha>0\right)$, guarantees that $\mathrm{CU}$ is always preferred to the MFN by the government, even when it values firm contributions and firms prefer MFN.

Politically Viable Agreements: Since customs unions are so successful in raising government payoff, it is a corollary that forming such a trade agreement is always an equilibrium of the ratification subgame:

Corollary 1. There is always an equilibrium where a customs union is formed

Proof. By proposition 1, the government payoff is maximised under CU among all possible bilateral agreements. This implies that there is no profitable deviation to another RTA when both countries propose CU, and hence formation of $\mathrm{CU}$ is always an equilibrium.

Customs unions are "politically dominant" over other RTAs, and this is reflected in the world integration experience of recent decades. On the theory side, the logic of the model is clear: in the agreement ratification stage, CU must dominate over MFN and FTA from a government payoff perspective. This does not rule that another agreement may be ratified - for example, Ornelas (2005a) studies the welfare properties of equilibria where government payoff under FTA exceeds MFN, and hence FTA is politically viable. Importantly, in our extended model, adoption of an FTA or failure to agree on any RTA (i.e MFN) arise due to coordination failure. This begs the question whether the dominance of CUs is an artifact of our assumptions, or provides an interesting new look at the world of 
regional integration. Our empirical work in section 2 firmly suggests the latter: much of the growth in FTAs in the 1990s was driven by preparation for the Eastern Enlargement of the European Union, or restoration of soviet economic links in the CIS $^{11}$ (Schott, 2011); in practice - although not in the datasets commonly used by researchers - many FTAs have since been superseded by CUs. Second, even adopting a relatively strict standard on CU implementation, outside of North America and Asia, the important regional trade links of the world are increasingly managed through customs unions.

Customs unions may be hampered by exogenous political or institutional constraints. As Crawford and Fiorentino (2005) and Fiorentino et al. (2007) discuss, political alliances are, in practice, determinants of the formation of both FTA and CU. Perhaps coordination failures are more likely among governments that are not politically aligned, or disagreement on non-economic issues could delay the adoption of an otherwise politically viable CU. Second, our analysis presupposes that a supranational organization is formed in such a way that it sets the external tariff to maximize joint government payoff. Facchini et al. (2013) demonstrate that a $\mathrm{CU}$ with strategic delegation may yield poor outcomes: the median voter in each country is tempted to strategically delegate a highly protectionist representative to the $\mathrm{CU}$ commission; but this then causes the $\mathrm{CU}$ to set extraordinarily high tariffs; in their setting, a CU may fail to be formed for some parameter cases.

The political dominance of customs unions has important implications for models that study properties of politically viable FTAs. For example, Ornelas (2005a, corollary 2) states that "every country gains when an FTA is formed": FTAs

\footnotetext{
${ }^{11}$ Commonwealth of Independent States.
} 
benefit third countries, due to lower tariffs, and welfare reducing FTAs cannot be ratified in the potential partner countries. Our result indicates that this view may be short-sighted: in the longer run, standard arguments lead on to expect that a CU should be implemented instead of the coordination failure equilibrium of FTA. But CUs have negative welfare consequences to third countries; thus, a careful welfare assessment of RTAs is needed in this more general model.

Welfare Trade--Offs Among RTAs: When governments are politically biased, they will not implement optimal policies from a social welfare perspective. However, depending on the trade regime in place, distortions take somewhat different forms. Figure 3 summarizes the comparative statics of tariffs with respect to political bias in the different cases: compared to the member welfare-maximising tariff levels, FTAs are too liberal and CUs (weakly) too protectionist; MFN - since all trade is covered by tariffs - is the most protectionist. Adopting a "second-best" perspective, this section investigates which trade regime provides the highest member social welfare in this setting.

Interestingly, lobbying is not necessarily welfare reducing. While in a CU, political bias necessarily hurts member welfare, in an FTA, stronger lobbying necessarily increases social welfare. The reason being that tariffs are initially too low from a welfare perspective, so - whatever the motive for raising tariffs - leads to better welfare outcomes. This is the central result of the following proposition:

Proposition 2. As political bias in member countries increases,

i. member social welfare under FTA increases

ii. member social welfare under $C U$ decreases 
Figure 3: Comparison of Trade Regimes: Tariffs and Comparative Statics under Political Bias

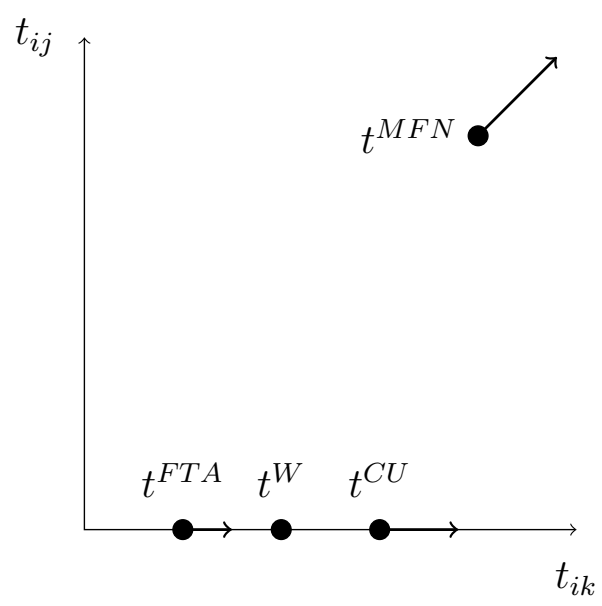

Proof.

i. member social welfare under FTA increases

The welfare change as the government bias changes in FTA is given below.

The social welfare that was defined in (1) does not directly depend on the political bias but only through the tariff changes. Thus we apply the chain rule due to changes in the tariff of the respective member as a result of the change in the bias:

$$
\begin{aligned}
& \frac{d W_{i}^{F T A}}{d \alpha}=\frac{\partial W_{i}^{F T A}}{\partial t_{i k}} \frac{\partial t_{i k}^{F T A}}{\partial \alpha}+\frac{\partial W_{i}^{F T A}}{\partial t_{j k}} \frac{\partial t_{j k}^{F T A}}{\partial \alpha} \\
& \frac{\partial W_{i}^{F T A}}{\partial t_{i k}} \frac{\partial t_{i k}^{F T A}}{\partial \alpha}=\frac{\partial\left(G_{i}^{F T A}-\alpha \Pi_{i}^{F T A}\right)}{\partial t_{i k}} \frac{\partial t_{i k}^{F T A}}{\partial \alpha}=-\alpha \frac{d \Pi_{i i}^{F T A}}{d \alpha}
\end{aligned}
$$

The second equality follows from the following two observations: 


$$
\begin{aligned}
\frac{\partial G_{i}^{F T A}}{\partial t_{i k}^{F T A}} & =0 \text { and } \frac{\partial \alpha \Pi_{i}^{F T A}}{\partial t_{i k}}=\frac{\partial \alpha \Pi_{i i}^{F T A}}{\partial t_{i k}} \\
& \frac{\partial W_{i}^{F T A}}{\partial t_{j k}} \frac{\partial t_{j k}^{F T A}}{\partial \alpha}=\frac{\partial \Pi_{j i}^{F T A}}{\partial t_{j k}} \frac{\partial t_{j k}^{F T A}}{\partial \alpha}=\frac{d \Pi_{j i}^{F T A}}{d \alpha}
\end{aligned}
$$

Combining the first and second partial derivatives we obtain:

$$
\frac{d W_{i}^{F T A}}{d \alpha}=-\alpha \frac{d \Pi_{i i}^{F T A}}{d \alpha}+\frac{d \Pi_{j i}^{F T A}}{d \alpha}=(1-\alpha) \frac{d \Pi_{i i}^{F T A}}{d \alpha}>0
$$

as $\alpha<1$ whenever there is positive trade with the rest of the world and $\Pi_{i i}^{F T A}=\Pi_{j i}^{F T A}$ in FTA.

ii. member social welfare under $\mathrm{CU}$ decreases

Again, social welfare is impacted by the change in the bias through the tariff changes. In the case of the $\mathrm{CU}$, there are no two different tariffs but a common external tariff $t_{i k}=t_{j k}=t_{k}$

$$
\begin{gathered}
\frac{d W_{i}^{C U}}{d \alpha}=\frac{\partial W_{i}^{C U}}{\partial t_{k}} \frac{\partial t_{k}^{C U}}{\partial \alpha}=\frac{\partial\left(G_{i}^{C U}-\alpha \Pi_{i}^{C U}\right)}{\partial t_{k}} \frac{\partial t^{C U}}{\partial \alpha}, \\
\frac{\partial G_{i}^{C U}}{\partial t_{k}^{C U}}=0=>\frac{d W_{i}^{C U}}{d \alpha}=-\frac{\alpha d \Pi_{i}^{C U}}{d \alpha}<0
\end{gathered}
$$

The central contribution of this proposition is to show that political bias raises social welfare under FTA in absolute terms, while earlier results established only 
"differences in differences"12. For example, in Ornelas (2005a, proposition 4), it is shown that FTA improves member welfare by more relative to MFN, the stronger the political bias. We now turn to the comparison of CU with MFN, where a differences in differences result is of interest:

Proposition 3. As political bias increases, member social welfare under MFN decreases faster than under $C U$

Proof. First, let us describe the welfare change in the MFN regime as the political bias is increasing. Under the MFN the countries do not discriminate among other countries, hence $t_{i k}=t_{i j}=t_{i}^{M F N}$ and $t_{j k}=t_{j i}=t_{j}^{M F N}$

$$
\begin{aligned}
& \frac{d W_{i}^{M F N}}{d \alpha}=\frac{\partial W_{i}^{M F N}}{\partial t_{i}} \frac{\partial t_{i}^{M F N}}{\partial \alpha}+\frac{\partial W_{i}^{M F N}}{\partial t_{j}} \frac{\partial t_{j}^{M F N}}{\partial \alpha}, \\
& \frac{d W_{i}^{M F N}}{d \alpha}=\frac{\partial\left(G_{i}^{M F N}-\alpha \Pi_{i}^{M F N}\right)}{\partial t_{i}} \frac{\partial t_{i}^{M F N}}{\partial \alpha}+\frac{\partial \Pi_{j i}^{M F N}}{\partial t_{j}} \frac{\partial t_{j}^{M F N}}{\partial \alpha}=> \\
& \frac{d W_{i}^{M F N}}{d \alpha}=-\frac{\alpha \partial \Pi_{i i}^{M F N}}{\partial t_{i}} \frac{\partial t_{i}^{M F N}}{\partial \alpha}+\frac{\partial \Pi_{j i}^{M F N}}{\partial t_{j}} \frac{\partial t_{j}^{M F N}}{\partial \alpha}<0,
\end{aligned}
$$

where the last expression equality follows from the following two observations: $\frac{\partial G_{i}^{M F N}}{\partial t_{i}^{M F N}}=0$ and $\frac{\partial \alpha \Pi_{i}^{M F N}}{\partial t_{i}^{M F N}}=\frac{\partial \alpha \Pi_{i i}^{M F N}}{\partial t_{i}^{M F N}}$ The welfare in MFN is decreasing as the bias increases as both channels, the two components of $\frac{d W_{i}^{M F N}}{d \alpha}$, are negative. As the political motivations of the government lead to welfare decrease both in MFN and CU, we should look at the difference:

$$
\frac{d W_{i}^{M F N}}{d \alpha}-\frac{d W_{i}^{C U}}{d \alpha}=-\frac{\alpha d \Pi_{i i}^{M F N}}{d \alpha}+\frac{d \Pi_{j i}^{M F N}}{d \alpha}-\left(-\frac{\alpha d \Pi_{i}^{C U}}{d \alpha}\right)
$$

\footnotetext{
${ }^{12}$ We thank Emanuel Ornelas for pointing this out
} 


$$
\begin{aligned}
& =-\frac{\alpha d \Pi_{i i}^{M F N}}{d \alpha}+\frac{d \Pi_{j i}^{M F N}}{d \alpha}+\frac{\alpha d \Pi_{i i}^{C U}}{d \alpha}+\frac{\alpha d \Pi_{j i}^{C U}}{d \alpha} \\
& =\alpha\left(\frac{d \Pi_{i i}^{C U}}{d \alpha}+\frac{d \Pi_{j i}^{C U}}{d \alpha}-\frac{d \Pi_{i i}^{M F N}}{d \alpha}\right)+\frac{d \Pi_{j i}^{M F N}}{d \alpha} \\
& =\alpha\left(\frac{\partial \Pi_{i i}^{C U}}{\partial t_{k}} \frac{\partial t_{k}^{C U}}{\partial \alpha}+\frac{\partial \Pi_{j i}^{C U}}{\partial t_{k}} \frac{\partial t_{k}^{C U}}{\partial \alpha}-\frac{\partial \Pi_{i i}^{M F N}}{\partial t_{i}} \frac{\partial t_{i}^{M F N}}{\partial \alpha}\right)+\frac{\partial \Pi_{j i}^{M F N}}{\partial t_{j}} \frac{\partial t_{j}^{M F N}}{\partial \alpha} \\
& =\alpha\left(2 \frac{2 n\left(\Gamma+n t_{k}^{C U}\right)}{(3 n+1)^{2}} \frac{\partial t_{k}^{C U}}{\partial \alpha}-\frac{4 n\left(\Gamma+2 n t_{i}^{M F N}\right)}{(3 n+1)^{2}} \frac{\partial t_{i}^{M F N}}{\partial \alpha}\right)+\frac{\partial \Pi_{j i}^{M F N}}{\partial t_{j}^{M F N}} \frac{\partial t_{j}^{M F N}}{\partial \alpha}
\end{aligned}
$$

Now note the first part of the expression, the part in brackets, is negative as $t_{k}^{C U}<t_{j}^{M F N}$ and $\frac{\partial t_{k}^{C U}}{\partial \alpha}<\frac{\partial t_{j}^{M F N}}{\partial \alpha}$ by Lemma 2. The second part of the expression is negative, too, as in MFN firms from $i$ pay tariff when exporting to $j$, thus, their profit decreases as the tariff $t_{j}^{M F N}$ in $j$ increases. Hence,

$$
\frac{d W_{i}^{M F N}}{d \alpha}-\frac{d W_{i}^{C U}}{d \alpha}<0
$$

Having established the comparative statics of the trade regimes with respect to political bias, our interest turns to the critical question of levels: is it possible to state which regime provides the highest member social welfare?

Proposition 4. Member social welfare is maximised under CU vis-a-vis MFN and FTA, for any level of product market competition and any political bias consistent with positive trade with the rest of the world.

Proof. a) First, let us compare welfare under CU and FTA under the presence of possible bias of the government. When the government is benevolent, that is, $\alpha=$ 0 , then the viability and welfare coincide and we can apply the Proposition 1 . By 
Proposition 1, in this case the CU implements member welfare maximising tariffs, which obviously dominates the (lower) FTA tariffs. However, as per Proposition 2, as $\alpha$ increases, the welfare in the $\mathrm{CU}$ is decreasing and instead increasing in FTA. Thus to prove the result, it is sufficient to compare the welfare at the highest bias level where trade with the rest of the world is about to cease, i.e. $\alpha=\frac{1}{4 n}$. 3 .

Bearing in mind that due to linear demand the welfare function is quadratic and thus has an axis of symmetry going through the vertex. It follows that any two tariff levels equidistant from the vertex deliver the same welfare level. Further, by concavity, a tariff point that is closer to the vertex provides higher welfare than another point that has larger distance from the vertex. In order to compare the welfare under $\mathrm{CU}$ and FTA at $\alpha=\frac{1}{4 n}$, we analyse the distance from tariff of each regime from the tariff that maximizes social welfare, $t^{W}$. From Proposition 1 the $t^{W}$ is the tariff of benevolent government in CU, so we have to show that $\left|t^{C U}\left(\alpha=\frac{1}{4 n}\right)-t^{W}\right|<\left|t^{F T A}\left(\alpha=\frac{1}{4 n}\right)-t^{W}\right|$.

$$
\left|t^{C U}-t^{W}\right|=\frac{\Gamma}{1+2 n}-\frac{4 n \Gamma}{2(1+2 n)^{2}+n}
$$

Similarly, the distance between FTA and welfare maximising tariff is

$$
\left|t^{F T A}-t^{W}\right|=\frac{4 n \Gamma}{2(1+2 n)^{2}+n}-\frac{\Gamma\left(2 n+\frac{3}{2}\right)}{\left(\frac{1}{2}+2 n\right) n+2(1+2 n)^{2}}
$$

Then,

$$
\left|t^{F T A}-t^{W}\right|-\left|t^{C U}-t^{W}\right|=\frac{\Gamma(3 n+1)\left(32 n^{3}+4 n^{2}-17 n-6\right)}{(2 n+1)\left(8 n^{2}+9 n+2\right)\left(20 n^{2}+17 n+4\right)}>, 0
$$

The inequality follows because $n \geq 1$, and hence each bracket is of positive sign. Thus, member social welfare under $\mathrm{CU}$ is higher at $\alpha=\frac{1}{4 n}$.

The intuition for the result depends on the trade regime being compared with 
CU. When comparing the FTA and CU, it is the welfare result with a politically motivated government is counter-intuitive. Indeed, as government places higher weight on the firms' interests, the social welfare in the customs union is decreasing. At the same time, the less benevolent the government, the higher the social welfare under the FTA! However we show that with any number of firms and government bias, the coordination brought by $\mathrm{CU}$ gives such a strong welfare boost that as long as the $\mathrm{CU}$ is not in autarky, it provides higher welfare. The intuition is the following: if the number of firms in member countries is low, then the coordination gain of the $\mathrm{CU}$ is very strong and remains, albeit diminished, even when the bias increases. And when the number of firms is large, i.e. the markets are more competitive, then the extra protectionism that the $\mathrm{CU}$ and political bias bring are limited as there are low returns from protectionism, again putting the coordination gains of the CU above the losses even when the government's objective is politically motivated.

One can find examples with strong political bias, where the CU already ceased external trade, but the FTA is actually quite close to implementing the memberwelfare maximising tariff. What the proposition shows is that trade with the rest of the world being positive under $\mathrm{CU}$ is a sufficient condition to ensure that member welfare is also higher under CU than FTA. The link to the non-members positive exports is also intuitive: the bias, while affecting the members, also has a strong negative impact on non-member exports. We think this particular bound is interesting because it's a very conservative requirement and can easily be observed empirically.

Customs unions also imply greater member welfare than under MFN. As the preceding discussion showed, the MFN regime implies by far the highest "tariff 
wall". Implementation of a CU improves market access in the partner country - benefiting producer profits - and reduces the prices consumers face, as tariffs are either eliminated (with respect to the partner country), or reduced (vis-a-vis the rest of the world). Thus, the welfare advantages of the $\mathrm{CU}$ as a function of the political bias are rather straightforward: as the bias goes up, the CU is less protectionst relative to MFN while still providing the gains from coordination. However, as we saw in the previous section, the viability is not straightforward and not monotone, depending on the competitiveness in each country.

Our results thus extend the earlier findings in several dimensions: comparing CU both to FTA and MFN, while allowing for politically motivated government and allowing arbitrary number of firms $n$ in member countries. Interestingly, the $\mathrm{CU}$ is thus preferred both to a more liberal regime (FTA) and more protectionist one $(\mathrm{MFN})$.

Impact on Outsiders and Global Welfare: Yi (1996) shows that the formation of a customs union with benevolent governments reduces the welfare of non-members compared to the MFN setting. And the position of the non-members is worsening as the number of countries in a customs union increases. The presence of the political motivations of the governments only makes negative impact stronger. At the same time, the global welfare is higher under a customs union. Indeed, the positive tariffs increase the distortions of the imperfect competition by reducing the total production. Thus, as the customs union has lower tariffs than the MFN world, aggregate welfare increases. 


\section{Border costs and asymmetric production}

This section relaxes some of the assumptions of the model to consider the equilibrium outcomes for a more general and realistic setting. First, we look at the impact of non-tariff border costs of trade. Unlike MFN or FTA, customs union can alleviate internal non-tariff costs. We find that the presence of the border costs has tariff reduction effect on the customs union tariff. This effect works in the opposite direction to the coordination effect, thus balancing the tariff increase associated with the move from an FTA to the CU. As we discuss below, this is in line with the empirical findings that the $\mathrm{CU}$ leads to moderately higher tariffs than in FTA. Second, we extend the standard model by incorporating the asymmetric production structure. We consider a case where the rest of the world produces all goods while the countries that would form a trade agreement each produce different imperfectly competitive goods. That structure replicates Facchini et al. (2013), but without their assumption on the delegation. We find that our results regarding the political viability and welfare dominance of the $\mathrm{CU}$ relative to other two agreements hold. This implies that both asymmetric production structure and the delegation assumption, as in Facchini et al. (2013), are necessary to obtain parameter intervals where the customs union is not formed.

\subsection{Trade Costs and Border Effects}

Customs unions are highly effective in raising bilateral trade. As Roy (2010) shows, when two countries form a CU with each other, trade between them on average doubles after ten years, while gains from FTA are much smaller. Standard theory indeed predicts that a CU should lead to an increase in trade between partners, driven by a higher external tariff, although the predicted magnitude is 
smaller. This may be due to the omission of border effects in the model; here, we present an extension allowing for $\mathrm{CU}$ members to close internal customs point and hence reducing trade costs. This has two effects: it mitigates, and possibly overturns, increases in the external tariff vis-a-vis FTA; and considerably strengthens the trade-creating effect of a CU. Since number of CU member countries, both in Africa and Eurasia, also score poorly on the World Bank's Trading Across Borders index, reductions in non-tariff costs may be important in understanding the apparent success of CU (see also Krueger (1997) in alleviating rules of origin (ROO) issues; see also Stoyanov (2012) for ROO issues in Canada-US trade.

We now augmented the model to allow for real trade costs. Let $c_{i j}$ be the non-tariff cost, per unit, incurred when trading from country $i$ to country $j$. The border costs, present under MFN, do not get abolished also under a free trade agreement. Indeed, the latter only sets the tariff costs to zero but the border crossings and ROO remain. Customs union, instead, provides an opportunity to remove the border costs through the abolishment of the ROO and, frequently, the internal customs controls. We will now see how the exogenous reduction in border costs associated with the customs union affects the external tariff in the CU.

The per-unit trade cost enters the model as a marginal cost incurred by all exporting firms in the MFN and FTA but not by domestic firms. In the customs union the border cost is only born by the exporting firms from the rest of the world due to the reduction in internal trade costs in the $\mathrm{CU}$. Below is the government objective in the $\mathrm{CU}, G_{C U}$, with the altered firm cost function: 


$$
\begin{aligned}
G_{C U} & =\frac{\left(3 \Gamma n-n\left(t_{i k}+c_{i j}+c_{i k}\right)\right)^{2}}{2(3 n+1)^{2}}+n t_{i k} \frac{\left(\Gamma-(1+2 n)\left(t_{i k}+c_{i k}\right)+n c_{i j}\right)}{3 n+1}+ \\
& +(1+\alpha) n \frac{\left(\Gamma+n\left(t_{i k}+c_{i k}\right)\right)^{2}}{(3 n+1)^{2}}+(1+\alpha) n \frac{\left(\Gamma+n\left(t_{i k}+c_{j k}-c_{j i}\right)\right)^{2}}{(3 n+1)^{2}}
\end{aligned}
$$

Similar to the tariff complementarity effect we discussed earlier, a reduction in trade $\operatorname{cost} c_{i j}$ then leads to a fall in the external tariff of a CU:

Proposition 5. The larger the reduction in internal trade costs in a $C U$, the more the external tariff falls

Proof. After augmenting the model with trade $\operatorname{costs} c_{i k} \geq 0$, and solving for external tariff analogously to the procedure in baseline model, one finds the first order conditions for $t_{i k}$ :

$$
\begin{gathered}
-\frac{n\left(3 \Gamma n-n\left(t_{i k}+c_{i j}+c_{i k}\right)\right.}{(3 n+1)^{2}}+\frac{n\left(\Gamma-(1+2 n)\left(t_{i k}+c_{i j}\right)+n c_{i j}\right.}{3 n+1}+\frac{-(1+2 n) n t_{i k}}{3 n+1}+ \\
+\frac{2(\alpha+1) n^{2}\left(\Gamma+n\left(t_{i k}+c_{i k}\right)\right)}{(3 n+1)^{2}}+\frac{2(\alpha+1) n^{2}\left(\Gamma+n\left(t_{i k}+c_{j k}-c_{j i}\right)\right)}{(3 n+1)^{2}}=0
\end{gathered}
$$

Apply implicit differentiation to obtain the result:

$$
\frac{t^{C U}}{d c_{i j}}=-\frac{n(3 n+2)}{(1-4 \alpha n) n+2(2 n+1)^{2}}>0
$$

Since $\alpha<\frac{1}{4 n}$ by assumption 1 , the expression is positive. Hence a reduction in internal trade costs leads to a lower external tariff, as claimed.

Reduction in trade costs provide a further rationale for CU formation, which also attenuates adverse effects on non-member countries. Aside from the direct positive welfare effect of a reduction in trade costs, tariff complementarity forces also lead to a reduction in the external tariff once internal borders are eliminated. 
This may offset some of the tariff increase expected when a CU is formed. Empirical evidence from both MERCOSUR and the Eurasian Customs Union showed typically mild tariff increases after $\mathrm{CU}$ formation, consistent with the effect of reduced trade costs (Mkrtchyan, 2013).

\subsection{Asymmetric Production}

We now extend the baseline model to incorporate asymmetric production structures. As in Facchini et al. (2013), we now consider the case of two imperfectly competitive goods; each of the potential partner countries has $n$ firms, but produces only one of the goods. In the rest of the world, both goods are produced by $n$ firms each. Letting $x$ denote the good produced in country i, and $y$ the good produced in country $j$, we have the following production structure:

$$
\left[\begin{array}{lll}
n & 0 & n \\
0 & n & n
\end{array}\right]
$$

The utility function is linear-quadratic in each good, directly generalising from the baseline above. All other elements of the model remain unchanged. It follows that the best response functions of each firm remains the same. The government, however, now sets two tariff lines: one for the good produced domestically, and one for the imported good. This yields the following optimal external tariffs:

Proposition 6. External Tariffs under Asymmetric Production

i. The external tariff for the domestically produced good a is invariant to the trade regime: $t_{i, a}^{M F N}=t_{i, a}^{F T A}=t_{i, a}^{C U}$

ii. The external tariff on the non-produced good $b$ is lowest in FTA, intermediate in MFN and highest under $C U: t_{i, b}^{F T A}<t_{i, b}^{M F N}<t_{i, b}^{C U}$. 
Proof. See Appendix

In the asymmetric production setting, $\mathrm{CU}$ is now the most protectionist trade regime. For the domestically produced good, government incentives for tariff setting do not change when a RTA is formed with the partner country: there is, by construction, no competition from firms in the partner country when an FTA is formed - hence removing the tariff complementarity effect. When forming a CU, due to symmetric utility functions, the CU objective for setting of the external tariff simply becomes a monotonic transformation of the original problem; this also leaves tariffs unchanged. Tariffs on the good that is fully imported are lowest under the - due to tariff complementarity, since the country already committed to a zero internal tariff with the partner. In contrast to the symmetric setting, tariffs under MFN are now lower than under CU. Tariffs are highest under the CU because profit effects are fully internalised.

These differences in tariff structures do not affect results on political viability and member welfare of $\mathrm{CU}$ compared to the baseline setting. In the $\mathrm{CU}$ the tariff on the good that is not produced domestically is matched to the level of the partner country tariff. Thus it is clear that the consumer surplus and tariff revenue for the only-import good in the $\mathrm{CU}$ is lower than under the MFN and FTA, - the country engages in extra protection the good it has no firms in. However the upside comes from gaining similar protection in the domestically produced good in the partner country. The home country extends fully its level of protection to the partner. The trade-off between the losses in the only-import good and gains in the home-produced good define the overall outcome. Hence,

Proposition 7. $\quad i$. There is always an equilibrium where a $C U$ is formed 
ii. Member social welfare is maximised under $C U$, as long as trade with the rest of the world does not cease.

Proof. See Appendix

Intuitions from the symmetric model carry over to the asymmetric extension. In particular, political viability of $\mathrm{CU}$ is promoted by the fact that cross-border profit externalities are internalised under $\mathrm{CU}$; this benefits lobbies, in particular when $\alpha$ is large and hence the external tariff is high. However, member social welfare is still promoted by the CU: the tariff on the non-produced good is inefficiently low, and by "trading protection", the countries achieve a welfare improvement. As long as trade with the rest of the world does not cease in either product, the member welfare improvement in fact dominates the inefficiency brought by excessively high political tariffs under $\mathrm{CU}$.

\section{Conclusion}

Customs unions have rapidly proliferated in recent decades. We demonstrate that this important observation remains frequently unnoticed when regional trade agreements are assessed based on their sheer number. We provide new insights by demonstrating both the spread and increase in CU membership across several continents by looking at the bilateral country pairs and an agreement type they chose for trade. Further, we researched and identified the customs unions with the implemented common external tariff and traced the membership growth over the recent decades. Motivating our suggestion of the success of the CUs, we show that over the years that many weaker agreements (partial scope agreements and free trade agreements) were often maturing into a customs union. Some of them, 
such as the numerous FTAs among eastern EU members, presenting an impressive increase in the number of FTAs, were signed specifically with a goal to be later turned into the European Union CU.

These empirical facts on the silent success of the customs unions are supported by theory. We extend a common model used in the regional integration literature to include all types of bilateral trade agreements, generalise the competitive structure to have more than one firm in each country, consider symmetric and asymmetric production structures and allow for a politically motivated government. We show that customs unions dominate all other bilateral agreements, including those not permitted under GATT XXIV due to violation of the zero internal tariff requirement, from a political objective perspective. This dominance is driven by improved management of cross-border elasticities as well as greater scope for protection of profits, especially important when governments are subject to lobbying pressures. But we also show that CUs improve the social welfare of member states, so long as trade with the rest of the world does not cease entirely. Thus, customs unions can be an engine for development for member countries.

These results highlight the importance of customs unions to our understanding of preferential trade and its consequences. In particular, the static gains from FTAs to third countries - due to tariff complementarity - may not last long if FTAs then turn into CUs. On the other hand, CUs can bring welfare benefits to member countries, and may lead to a reduction in trade costs that could not be achieved under FTA. 


\section{Appendix}

\subsection{Market Outcomes}

The problem of any of the $n$ firms in, say, country $i$ is given by

$$
\begin{aligned}
\max _{\left\{q_{i i}, q_{j i}, q_{k i}\right\}} & =P\left(\bar{Q}_{i}, q_{i i}\right) q_{i i}+\left(P\left(\bar{Q}_{j}, q_{j i}\right)-t_{j i}\right) q_{j i} \\
& +\left(P\left(\bar{Q}_{k}, q_{k i}\right)-t_{k i}\right) q_{k i}
\end{aligned}
$$

where $\bar{Q}_{j}$ denotes the total quantity produced in the market by all other firms, and $Q_{j}$ denotes the market output.

And similarly for firms in the other countries, $j$ and $k$. To find the equilibrium in country $j$, sum the $3 n$ first-order conditions for $q_{i i}, q_{i j}, q_{i k}$ respectively to find the equilibrium output for given tariffs:

$$
\begin{aligned}
0 & =3 n\left(\Gamma-Q_{x}\right)-Q_{x}-n t_{j i}-n t_{j k} \\
Q_{j}^{*}\left(t_{j i}, t_{j k}\right) & =\frac{3 n \Gamma-n\left(t_{j i}+t_{j k}\right)}{3 n+1} \\
P\left(Q _ { j } ^ { * } \left(t_{j i}, t_{j k}\right.\right. & =\Gamma-Q_{j}^{*}\left(t_{j i}, t_{j k}\right)=\frac{\Gamma+n\left(t_{j i}+t_{j k}\right)}{3 n+1}
\end{aligned}
$$

and, again, symmetrically for the other countries. The output of the representative firm in each country is then given by

$$
\begin{aligned}
q_{j j}^{*} & =\frac{\Gamma+n\left(t_{j i}+t_{j k}\right)}{3 n+1} \\
q_{j i}^{*} & =\frac{\Gamma-(1-2 n) t_{j i}+n t_{j k}}{3 n+1} \\
q_{j k}^{*} & =\frac{\Gamma+n t_{j i}-(1+2 n) t_{j k}}{3 n+1}
\end{aligned}
$$


6.2. Welfare Components objective given the market outcomes

$$
\begin{aligned}
C S_{i}\left(t_{j i}, t_{j k}\right) & =\left(\Gamma-P\left(Q_{j}^{*}\left(t_{j i}, t_{j k}\right)\right) Q_{j}^{*}\left(t_{j i}, t_{i k}\right)-\frac{Q_{i}^{*}\left(t_{j i}, t_{j k}\right)^{2}}{2}\right. \\
& =\frac{Q_{j}^{*}\left(t_{j i}, t_{j k}\right)^{2}}{2}=\frac{3 n \Gamma-n\left(t_{j i}+t_{j k}\right)^{2}}{2(3 n+1)^{2}} \\
T R_{i}\left(t_{j k}, t_{j k}\right) & =n\left(q_{j i}^{*} t_{j i}+q_{j k}^{*} t_{j k}\right) \\
& =\frac{\Gamma\left(t_{j k}+t_{j i}\right)+2 n t_{j i} t_{j k}-(2 n+1)\left(t_{j k}^{2}+t_{j i}^{2}\right)}{3 n+1} \\
\Pi_{i i}\left(t_{j i}, t\right) & =n\left(\pi_{i i}^{*}+\pi_{j i}^{*}+\pi_{k i}^{*}\right)=n\left(\left(q_{i i}^{*}\right)^{2}+\left(q_{j i}^{*}\right)^{2}+\left(q_{k i}^{*}\right)^{2}\right)
\end{aligned}
$$

Now, in each trade regime these become:

a) MFN, $t_{i} j=t_{i} k=t$

$$
\begin{aligned}
\Pi_{i}^{M F N} & =\Pi_{i i}^{M F N}+\Pi_{j i}^{M F N}=\frac{n(\Gamma+2 n t)^{2}}{(3 n+1)^{2}}+\frac{n(\Gamma-(1+n) t)^{2}}{(3 n+1)^{2}} \\
C S_{i}^{M F N} & =\frac{(3 \Gamma n-2 n t)^{2}}{2(3 n+1)^{2}} \\
T R_{i}^{M F N} & =\frac{2 n t^{M F N}((-n-1) t+\Gamma)}{3 n+1} \\
G_{i}^{M F N} & \left.=C S^{M F N}+T R^{M F N}+(1+\alpha) \Pi_{i}^{M F N}\right)
\end{aligned}
$$

b) FTA or CU, $t_{i} j=0, t_{i} j=t$

$$
\begin{aligned}
\Pi_{i}^{C U} & =\Pi_{i i}^{C U}+\Pi_{j i}^{C U}=\frac{2 n(\Gamma+n t)^{2}}{(3 n+1)^{2}} \\
\Pi_{i i}^{C U} & =\Pi_{j i}^{C U}=\frac{(n t+\Gamma)^{2}}{(3 n+1)^{2}} \\
C S_{i}^{C S} & =\frac{(3 \Gamma n-n t)^{2}}{2(3 n+1)^{2}} \\
T R_{i}^{C U} & =\frac{n t^{C U}((-2 n-1) t+\Gamma)}{3 n+1} \\
G_{i}^{C U} & =\frac{2(\alpha+1) n(n t+\Gamma)^{2}}{(3 n+1)^{2}}+\frac{(3 \Gamma n-n t)^{2}}{2(3 n+1)^{2}}+\frac{n t((-2 n-1) t+\Gamma)}{3 n+1}
\end{aligned}
$$


6.3. Welfare Components given the Market Outcomes and Government Tariff Pol$i c y$

$$
\begin{aligned}
& \text { At } t=t^{M F N} \\
& \qquad \begin{aligned}
G_{i}^{M F N} & =C S_{i}^{M F N}+T R_{i}^{M F N}+(1+\alpha)\left(\Pi_{i i}^{M F N}+\Pi_{j i}^{M F N}\right) \\
G_{i}^{M F N} & =\frac{\Gamma^{2} n^{2}((2 \alpha-1) n-2)^{2}}{2\left(n(1-2 \alpha n)+(1+n)^{2}\right)^{2}}+\frac{\Gamma^{2} n(1-2 \alpha n)(2 \alpha n+2 n+1)}{2\left(n(1-2 \alpha n)+(1+n)^{2}\right)^{2}} \\
& +(1+\alpha) n \frac{\Gamma^{2}(n+1)^{2}}{\left(n(1-2 \alpha n)+(1+n)^{2}\right)^{2}}+(1+\alpha) n \frac{\Gamma^{2}(1-2 \alpha n)^{2}}{4\left(n(1-2 \alpha n)+(1+n)^{2}\right)^{2}} \\
G_{i}^{M F N} & =\frac{\Gamma^{2} n(2 \alpha n-n-2 \alpha-3)}{2\left(n(1-2 \alpha n)+(1+n)^{2}\right)}+\frac{(\alpha+1) \Gamma^{2} n(2 \alpha n-1)^{2}}{4\left(n(1-2 \alpha n)+(1+n)^{2}\right)^{2}} \\
\Pi_{k i}^{M F N} & =\frac{\Gamma^{2}(2 \alpha n-1)^{2}}{4\left(n(1-2 \alpha n)+(1+n)^{2}\right)^{2}}
\end{aligned}
\end{aligned}
$$

At $t=t^{C U}$

$$
\begin{aligned}
G_{i}^{C U} & =C S_{i}^{C U}+T R_{i}^{C U}+(1+\alpha)\left(\Pi_{i i}^{C U}+\Pi_{j i}^{C U}\right) \\
G_{i}^{C U} & =\frac{\Gamma^{2} n^{2}(4 \alpha n-8 n-5)^{2}}{2\left(n(1-4 \alpha n)+2(1+2 n)^{2}\right)^{2}}+\frac{\Gamma^{2} n(1-4 \alpha n)(4 \alpha n+4 n+1)}{\left(n(1-4 \alpha n)+2(1+2 n)^{2}\right)^{2}} \\
& +(1+\alpha) 2 n \frac{4 \Gamma^{2}(2 n+1)^{2}}{\left(n(1-4 \alpha n)+2(1+2 n)^{2}\right)^{2}} \\
G_{i}^{C U} & =\frac{\Gamma^{2} n(4 \alpha n-8 n-8 \alpha-9)}{2\left(n(1-4 \alpha n)+2(1+2 n)^{2}\right)} \\
\Pi_{k i}^{C U} & =n \frac{\Gamma^{2}(4 \alpha n-1)^{2}}{\left(n(1-4 \alpha n)+2(1+2 n)^{2}\right)^{2}}
\end{aligned}
$$

\subsection{Example:Welfare components under $M F N$ and $C U$}

To illustrate how different trade-offs and distortions play out depending on the competitiveness level and government bias, consider the following example that looks at the extremes. First, the case of the monopoly firms in each country and, second, the case of 10 firms in each country. For each case we also look at the extremes of the political motivations: benevolent case and the political bias that would lead to autarky of the customs union. 
Table 2: Example: Welfare components under MFN and CU

\begin{tabular}{|c|c|c|c|c|c|}
\hline & & \multicolumn{2}{|c|}{$\mathrm{n}=1$} & \multicolumn{2}{|c|}{$\mathrm{n}=10$} \\
\hline & & $\alpha=0$ & $\alpha=0.25$ & $\alpha=0$ & $\alpha=0.025$ \\
\hline \multirow{2}{*}{ Total Profits } & $P S_{i}^{M F N}$ & $0.17 \Gamma^{2}$ & $0.20 \Gamma^{2}$ & $0.07 \Gamma^{2}$ & $0.076 \Gamma^{2}$ \\
\hline & $P S_{i}^{C U}$ & $0.199 \Gamma^{2}$ & $0.28 \Gamma^{2}$ & $0.04 \Gamma^{2}$ & $0.045 \Gamma^{2}$ \\
\hline \multirow{2}{*}{ Home Profits } & $P S_{i i}^{M F N}$ & $0.16 \Gamma^{2}$ & $0.198 \Gamma^{2}$ & $0.007 \Gamma^{2}$ & $0.008 \Gamma^{2}$ \\
\hline & $P S_{i i}^{C U}$ & $0.099 \Gamma^{2}$ & $0.111 \Gamma^{2}$ & $0.002 \Gamma^{2}$ & $0.002 \Gamma^{2}$ \\
\hline \multirow{2}{*}{ Partner Profits } & $P S_{j i}^{M F N}$ & $0.01 \Gamma^{2}$ & $0.03 \Gamma^{2}$ & $0.000 \Gamma^{2}$ & $0.000 \Gamma^{2}$ \\
\hline & $P S_{j i}^{C U}$ & $0.099 \Gamma^{2}$ & $0.111 \Gamma^{2}$ & $0.002 \Gamma^{2}$ & $0.002 \Gamma^{2}$ \\
\hline \multirow{2}{*}{ Consumer Surplus } & $C S^{M F N}$ & $0.18 \Gamma^{2}$ & $0.154 \Gamma^{2}$ & $0.4196 \Gamma^{2}$ & $0.4165 \Gamma^{2}$ \\
\hline & $C S^{C U}$ & $0.234 \Gamma^{2}$ & $0.222 \Gamma^{2}$ & $0.454 \Gamma^{2}$ & $0.454 \Gamma^{2}$ \\
\hline \multirow{2}{*}{ Tariff Revenue } & $T R^{M F N}$ & $0.06 \Gamma^{2}$ & $0.043 \Gamma^{2}$ & $0.001 \Gamma^{2}$ & $0.003 \Gamma^{2}$ \\
\hline & $T R^{C U}$ & $0.014 \Gamma^{2}$ & 0 & $0.001 \Gamma^{2}$ & 0 \\
\hline \multirow{2}{*}{ Gov-t Payoff } & $G^{M F N}$ & $0.41 \Gamma^{2}$ & $0.448 \Gamma^{2}$ & $0.496 \Gamma^{2}$ & $0.498 \Gamma^{2}$ \\
\hline & $G^{C U}$ & $0.447 \Gamma^{2}$ & $0.5 \Gamma^{2}$ & $0.499 \Gamma^{2}$ & $0.5 \Gamma^{2}$ \\
\hline
\end{tabular}

\subsection{Proofs of Lemmas}

Lemma 1. External Tariffs: Customs Union vs FTA

1. A free trade agreement imposes a strictly lower external tariff than a Customs Union, $t_{i k}^{F T A}<t_{i k}^{C U}$

2. The stronger the political bias, the more CU external tariff exceeds FTA

Proof. i. Under FTA, policy solves the first order condition of problem 4

$$
\frac{d G_{i}}{d t_{i k}^{F T A}}=\frac{d C S_{i}\left(\boldsymbol{t}_{i}^{F T A}\right)}{d t_{i k}^{F T A}}+\frac{d T R_{i}\left(\boldsymbol{t}_{i}^{F T A}\right)}{d t_{i k}^{F T A}}+(1+\alpha) \frac{d \Pi_{i i}\left(\boldsymbol{t}_{i}^{F T A}\right)}{d t_{i k}^{F T A}}=0
$$

Under a $\mathrm{CU}$, the first order condition of problem 3 is given by

$$
\frac{d G_{i}}{d t_{i k}}=\frac{d C S_{i}\left(\boldsymbol{t}_{i}\right)}{d t_{i k}}+\frac{d T R_{i}\left(\boldsymbol{t}_{i}\right)}{d t_{i k}}+(1+\alpha)\left(\frac{d \Pi_{i i}\left(\boldsymbol{t}_{i}\right)}{d t_{i k}}+\frac{d \Pi_{j i}\left(\boldsymbol{t}_{i}\right)}{d t_{i k}}\right)=0
$$


Evaluating the latter condition at the FTA tariff yields

$$
\left.\frac{d G_{i}}{d t_{i k}}\right|_{t_{i k}=t_{i k}^{F T A}}=0+(1+\alpha) \frac{d \Pi_{j i}\left(\boldsymbol{t}_{i}\right)}{d t_{i k}}>0
$$

Note that whenever the bias is not too high and the tariff is not prohibitive and we have interior solution, the objective of the government must be concave (second-order polynomial). Due to the concavity of $G_{i}(\boldsymbol{t})$, the tariff that solves the CU problem must be higher than the FTA level.

ii. Using the implicit function theorem on the first order conditions 16 and 17,

$$
\frac{d t_{i k}^{F T A}}{d \alpha}=\frac{d\left(\frac{d G_{i}\left(\boldsymbol{t}_{i}^{F T A}\right)}{d t_{i k}}\right) / d \alpha}{d\left(\frac{d G_{i}\left(\boldsymbol{t}_{i}^{F T A}\right)}{d t_{i k}}\right) / d t_{i k}}=-\frac{d \Pi_{i i}\left(\boldsymbol{t}_{i}^{F T A}\right) / d t_{i k}^{F T A}}{S O C^{F T A}}
$$

Similarly,

$$
\frac{d t_{i k}^{C U}}{d \alpha}=-\frac{d \Pi_{i i}\left(\boldsymbol{t}^{C} U_{i}\right) / d t_{i} z+d \Pi_{j i}\left(\boldsymbol{t}^{C} U_{i}\right) / d t_{i}^{C U}}{S O C^{C U}}
$$

Note that it is always the case that $S O C^{C U}>S O C^{F T A}$ as $S O C^{C U}>S O C^{F T A}+$ $d^{2} \Pi_{j i} / d t_{i k}^{2}$ and, hence, $-S O C^{F T A}>-S O C^{C U}>0$, the latter inequality comes due to concavity. Combining,

$$
\frac{d\left(t_{i k}^{C U}-t_{i k}^{F T A}\right)}{d \alpha}>-\frac{\left.\left(d \Pi_{i i}\left(\boldsymbol{t}_{i}^{C U}\right)-d \Pi_{i i}\right) / d t_{i k}\left(\boldsymbol{t}_{i}^{F T A}\right)\right)+d \Pi_{j i}\left(\boldsymbol{t}_{i}^{C U}\right)}{S O C^{C U}}=-\frac{d \Pi_{j i}\left(\boldsymbol{t}_{i}^{C U}\right)}{S O C^{C U}}>0(19
$$

as $\Pi_{j i}\left(\boldsymbol{t}_{i}^{C U}\right) \geq 0$, since the denominator is negative by concavity of the government objective $G_{i}(\boldsymbol{t})$, the overall product is positive.

Lemma 2. External Tariffs: Customs Union vs $M F N$

i. Under MFN, the external tariff is strictly higher than under Customs Union: $t_{i k}^{M F N}>t_{i k}^{C U}$

ii. The stronger the political bias, the more the MFN tariff exceeds the $C U$ external tariff 
Proof. $\quad$ i. The government's first order condition under MFN is

$$
\frac{d G_{i}}{d t_{i k}^{M F N}}=\frac{d C S_{i}\left(\boldsymbol{t}_{i}^{M F N}\right)}{d t_{i k}^{M F N}}+\frac{d T R_{i}\left(\boldsymbol{t}_{i}^{M F N}\right)}{d t_{i k}^{M F N}}+(1+\alpha) \frac{d \Pi_{i i}\left(\boldsymbol{t}_{i}^{M F N}\right)}{d t_{i k}^{M F N}}=0
$$

Substituting into the FOC of a customs union, 17, we obtain after some algebra

$$
\left.\frac{d G_{i}}{d t_{i k}}\right|_{\boldsymbol{t}=\boldsymbol{t}^{M F N}}=\frac{n^{2}\left(8 \alpha^{2} n^{2}+\alpha\left(16 n^{2}-6 n-4\right)+8 n^{2}-1\right)}{2(n+1)^{2}\left((1-2 \alpha) n^{2}+3 n+1\right)}<0
$$

Similarly to the previous case, whenever the solution is interior, $G_{i}(\boldsymbol{t})$ is concave in tariffs, the external tariff in CU must be lower than in MFN.

ii. Using the implicit function theorem on the first order conditions 20 and 17 ,

$$
\begin{aligned}
\frac{d t_{i k}^{M F N}}{d \alpha} & =-\frac{\Pi_{i i}\left(\boldsymbol{t}_{i}^{M F N}\right)}{d^{2} G_{i}\left(\boldsymbol{t}_{i}^{M F N}\right) / d t_{i k}^{M F N}} \\
\frac{d t_{i k}^{C U}}{d \alpha} & =-\frac{\Pi_{i i}\left(\boldsymbol{t}_{i}^{C U}\right)+\Pi_{j i}\left(\boldsymbol{t}_{i}^{C U}\right)}{d^{2} G_{i}\left(\boldsymbol{t}_{i}^{C U}\right) / d t_{i k}^{C U}}
\end{aligned}
$$

Substituting the required expressions,

$$
\frac{d t_{i}^{M F N}}{d \alpha}-\frac{d t^{C U}}{d \alpha}=\frac{4 n\left(\Gamma+2 n t^{M F N}\right)}{2(1+n)^{2}+(1-2 \alpha n) 2 n}-\frac{4 n\left(\Gamma+n t^{C U}\right)}{2(1+2 n)^{2}+(1-4 n \alpha) n}>0
$$

Both the nominator and denominator are positive as $t^{M F N}>t^{C U}$ and $\alpha<1 / 4 n$

Lemma 3. For any $n>1$ and any level government bias, firms prefer MFN over other trade regimes. In case of monopolies, $n=1$, the firms prefer customs union.

Proof. First, let us determine the comparative statics of profits in each regime. Let us look at 
the change of the profits with with respect to the government bias and number of firms.

$$
\frac{d \pi}{d \alpha}=\frac{d q^{2}}{d \alpha}=2 q \frac{d q}{d t} \frac{d t}{d \alpha}=>
$$

In case of the MFN: $\frac{d \pi_{i i}^{M F N}}{d \alpha}=2 q_{i i}^{M F N} \frac{q_{i i}^{M F N}}{d t} \frac{d t_{i}^{M F N}}{d \alpha}$

Similarly, for CU: $\frac{d \pi_{i}^{C U}}{d \alpha}=\frac{d \pi_{i i}^{C U}}{d \alpha}+\frac{d \pi_{j i}^{C U}}{d \alpha}=2 \frac{d \pi_{i i}^{C U}}{d \alpha}=2 * 2 q_{i i}^{C U} \frac{q_{i i}^{C U}}{d t} \frac{d t_{i}^{C U}}{d \alpha}$

$\frac{q_{i i}^{M F N}}{d t}=\frac{2 n}{3 n+1}$ and $\frac{q_{i i}^{C U}}{d t}=\frac{n}{3 n+1}$ (see Market Outcomes in Appendix).

Additionally, $\frac{q_{i i}^{M F N}}{d t}>\frac{q_{i i}^{C U}}{d t}$ and $\frac{d t_{i}^{M F N}}{d \alpha}>\frac{d t_{i}^{C U}}{d \alpha}$ by Lemma 2

It follows then

$$
\frac{d \pi_{i i}^{M F N}}{d \alpha}=2 q_{i i}^{M F N} \frac{2 n}{3 n+1} \frac{d t_{i}^{M F N}}{d \alpha}>2\left(q_{i i}^{C U} \frac{n}{3 n+1} \frac{d t_{i}^{C U}}{d \alpha}\right)=\frac{d \pi_{i}^{C U}}{d \alpha}
$$

$$
\frac{d \pi}{d n}=\frac{d q^{2}}{d n}=2 q \frac{d q}{d n}=>
$$

In case of the MFN: $\frac{d \pi_{i i}^{M F N}}{d n}=-2 q_{i i}^{M F N} \frac{3 \Gamma-2 t^{M F N}}{(3 n+1)^{2}}$

Similarly, for CU: $\frac{d \pi_{i}^{C U}}{d n}=\frac{d \pi_{i i}^{C U}}{d n}+\frac{d \pi_{j i}^{C U}}{d n}=2 \frac{d \pi_{i i}^{C U}}{d n}=2\left(2 q_{i i}^{C U} \frac{d q_{i i}^{C U}}{d n}\right)=-4 q_{i i}^{C U} \frac{3 \Gamma-t^{C U}}{(3 n+1)^{2}}$

It follows then

$$
\frac{d \pi_{i i}^{M F N}}{d n}=-2 q_{i i}^{M F N} \frac{3 \Gamma-2 t^{M F N}}{(3 n+1)^{2}}>-4 q_{i i}^{C U} \frac{3 \Gamma-t^{C U}}{(3 n+1)^{2}}=\frac{d \pi_{i}^{C U}}{d n}
$$

as $2 q_{i i}^{C U}>q_{i i}^{M F N}$ and $3 \Gamma-t^{C U}>3 \Gamma-2 t^{M F N}>0$ (see Market Outcomes).

Next, let us show the claim that for $n=1$ the profits in CU are higher than in MFN. We will do this for the highest possible bias of the government that leaves the $\mathrm{CU}$ members without trade 
with the rest of the world. This case is sufficient as, by comparative statics, it will be true for lower values of the bias: $\alpha=1 /(4 n)$

$$
\begin{aligned}
\pi_{i i}^{M F N}+\pi_{j i}^{M F N} & =\frac{\Gamma^{2}(n+1)^{2}}{\left(n(1-2 \alpha n)+(1+n)^{2}\right)^{2}}+\frac{\Gamma^{2}(2 \alpha n-1)^{2}}{4\left(n(1-2 \alpha n)+(1+n)^{2}\right)^{2}}=\frac{65 \Gamma^{2}}{36 * 9} \\
\pi_{i i}^{C U}+\pi_{j i}^{C U} & =2 \frac{4 \Gamma^{2}(2 n+1)^{2}}{\left(n(1-4 \alpha n)+2(1+2 n)^{2}\right)^{2}}=\frac{2 \Gamma^{2}}{9}
\end{aligned}
$$

So profits in CU are higher when $n=1$ as $2>65 / 36$ Finally, let us show that at $n=2$ the MFN profits are higher under MFN

\subsection{Proofs of Propositions}

Proof of Proposition 1: First, consider the problem of maximising the government objective of country i, subject only to tariffs being non-negative, i.e.

$$
\begin{aligned}
& \max _{\substack{\boldsymbol{t}_{i j} \geq 0 \\
\boldsymbol{t}_{i k} \geq 0}} G_{i}(\boldsymbol{t})=\max _{\substack{\boldsymbol{t}_{i j} \geq 0 \\
\boldsymbol{t}_{i k} \geq 0}} C S_{i}(\boldsymbol{t})+T R(\mathbf{t})+(1+\alpha)\left(\Pi_{i i}(\mathbf{t})+\Pi_{j i}(\mathbf{t})\right) \\
& \quad=\max _{\substack{\boldsymbol{t}_{i j} \geq 0 \\
\boldsymbol{t}_{i k} \geq 0}} \frac{Q_{i}^{2}(\boldsymbol{t})}{2}+n \mathbf{q}_{i}(\mathbf{t}) \mathbf{t}^{T}+(1+\alpha) n q_{i i}^{2}(\mathbf{t})+(1+\alpha) n q_{j i}^{2}(\mathbf{t})
\end{aligned}
$$

Remark: In any solution, $t_{i j}^{*} \leq t_{i k}^{*}$. Indeed, assume the opposite were true, and there was a solution where $t_{i k}^{*}<t_{i j}^{*}$. That implies $G_{i}\left(t_{i j}^{*}, t_{i k}^{*}\right) \geq G_{i}\left(t_{i k}^{*}, t_{i j}^{*}\right) . G_{i}^{H}(\mathbf{t})=C S_{i}(\boldsymbol{t})+T R(\mathbf{t})+(1+$ $\alpha) \Pi_{i i}(\mathbf{t})$ is a symmetric polynomial in $\left(t_{i j}, t_{i k}\right)$ and thus has the same value for permutations. However $(1+\alpha) \Pi_{j i}(\mathbf{t})$ is decreasing in $t_{i j}$ and increasing in $t_{i k}$ and thus $\Pi_{j i}\left(t_{i j}^{*}, t_{i k}^{*}\right)<\Pi_{j i}\left(t_{i k}^{*}, t_{i j}^{*}\right)$ as $t_{i k}^{*}<t_{i j}^{*}$. It follows that $G_{i}\left(t_{i j}^{*}, t_{i k}^{*}\right)<G_{i}\left(t_{i k}^{*}, t_{i j}^{*}\right)$ - contradiction to the assumption that $\left(t_{i j}^{*}, t_{i k}^{*}\right)$ was a solution.

Now, suppose first first were an interior solution with no constraint binding. By the first order conditions:

$$
\begin{aligned}
t_{i j}^{*} & =-\frac{(2 \alpha+1) \Gamma}{n+\alpha\left(2 n^{2} \alpha-4 n^{2}-5 n-2\right)} \\
t_{i k}^{*} & =-\frac{\Gamma \alpha(2(\alpha+1) n+1)}{n+\alpha\left(2 n^{2} \alpha-4 n^{2}-5 n-2\right)}
\end{aligned}
$$


Testing the second order condition: For a maximum, the function should be concave. This requires $|H|>0$ and $H(1,1)>0$, where $H=\left[\begin{array}{cc}n \frac{-2 n^{2}-n+2 \alpha\left(5 n^{2}+4 n+1\right)}{(3 n+1)^{2}} & n^{2} \frac{4 n+1-2 \alpha(n+1)}{(3 n+1)^{2}} \\ n^{2} \frac{4 n+1-2 \alpha(n+1)}{(3 n+1)^{2}} & n \frac{-8 n^{2}-9 n-2+4 \alpha n^{2}}{(3 n+1)^{2}}\end{array}\right]$ is the Hessian matrix of second order derivatives.

The $|H|=\frac{n+\alpha\left(2 n^{2} \alpha-4 n^{2}-5 n-2\right)}{(3 n+1)^{2}}$

It follows that $n+\alpha\left(2 n^{2} \alpha-4 n^{2}-5 n-2\right)>0$ is a necessary and sufficient condition for the concavity of the function and the local extremum being the global maximum.

However the extremum is outside of the feasible set wherever the function is concave, the internal tariff found with the FOC $t_{i j}<0$.

Wherever the function is concave, i.e. $n+\alpha\left(2 n^{2} \alpha-4 n^{2}-5 n-2\right)>0$, the function is monotone and decreasing on the right of the extremum and, hence, the constraint on non-negative tariffs is binding. The Remark implies then that $t_{i j}=0$ and $t_{i k} \geq 0$. The problem thus converges to that of the customs union.

When the function is not concave, i.e. $n+\alpha\left(2 n^{2} \alpha-4 n^{2}-5 n-2\right) \leq 0$, the borders of the feasible set and the prohibitive tariffs have to be considered. The Remark implies that either $t *_{i j}=0$ or $t *_{i k}=\overline{t_{i k}}$ is true in any solution.

Thus we are comparing the candidates of the form $\left(t *_{i j}, t *_{i k}\right)=\left(0, t_{i k}\right)$ to the candidates of the form $\left(t *_{i j}, t *_{i k}\right)=\left(t_{i j}, \overline{t_{i k}}\right)$.

Remember that $G\left(0, t_{i k}\right)$ is concave and maximised at $\left(t *_{i j}, t *_{i k}\right)=\left(0, t_{i k}^{C U}\right)$ for $\alpha \leq 1 /(4 n)$

Moreover, the function

$$
\begin{aligned}
G\left(t_{i j}, \overline{t_{i k}}\right) & =\frac{\left(\Gamma 2 n-t_{i j}\right)^{2}}{2(2 n+1)^{2}}-\frac{n t_{i j}\left(\Gamma-n\left(1+t_{i j}\right)\right)}{2 n+1}+\frac{(1+\alpha) n\left(\Gamma+n t_{i j}\right)^{2}}{(2 n+1)^{2}} \\
& +\frac{(1+\alpha) n+\left(\Gamma-n\left(1+t_{i j}\right)\right)^{2}}{(2 n+1)^{2}}
\end{aligned}
$$

is concave if the second order derivative $\frac{\partial^{2} G\left(t_{i j}, \overline{t_{i k}}\right)}{\partial t_{i j}^{2}}=n \frac{-n+\alpha\left(4 n^{2}+4 n+2\right)}{(2 n+1)^{2}}$

Thus wherever $\alpha<\frac{n}{4 n^{2}+4 n+2}$, the function is concave and the extremum is found at:

$$
t_{i j}=\frac{(2 \alpha+1) \Gamma}{-n+\alpha\left(4 n^{2}+4 n+2\right)}
$$

As the extremal point is negative when the function is concave, the function is maximized 
at $t_{i j}=0$ and the candidates of the form $\left(t_{i j}, \overline{t_{i k}}\right)$ collapse to $\left(0, \overline{t_{i k}}\right)$. And we know that for any $\alpha \leq 1 /(4 n)\left(0, t_{i k}^{C U}\right)$ is the solution of the function $G\left(0, t_{i k}\right)$.

Instead, if $\alpha \geq \frac{n}{4 n^{2}+4 n+2}$, the function $G\left(t_{i j}, \overline{t_{i k}}\right)$ is not concave. Thus the function reaches its highest point at either $t_{i j}=0$ or $t_{i j}=\overline{t_{i j}}$.

$$
\begin{aligned}
& G\left(0, \overline{t_{i k}}\right)=\frac{2 \Gamma^{2} n(n+\alpha+1)}{(2 n+1)^{2}} \\
& G\left(\overline{t_{i j}}, \overline{t_{i k}}\right)=\frac{\Gamma^{2} n(n+2 \alpha+2)}{2(n+1)^{2}} \\
& G\left(0, \overline{t_{i k}}\right)-G\left(\overline{t_{i j}}, \overline{t_{i k}}\right)=\frac{\Gamma^{2} n\left(3 n+2+2 \alpha\left(1-2 n^{2}\right)\right)}{2(n+1)^{2}(2 n+1)^{2}}>0 \text { for } \alpha \leq 1 /(4 n) \text { Thus, } G\left(\overline{t_{i j}}, \overline{t_{i k}}\right)<G\left(0, \overline{t_{i k}}\right)<
\end{aligned}
$$
$G\left(0, t^{C U}\right)$.

\section{Proof of Proposition 6:}

i. The problem in the MFN for good a is, as before,

$$
\begin{gathered}
t_{i, a}^{M F N}=\underset{t_{i, a}}{\operatorname{argmax}} G_{i}(\mathbf{t}) \\
\text { s.t. } \quad t_{i k, a}=t_{i l, a}
\end{gathered}
$$

while in the FTA the problem for good a is

$$
\begin{gathered}
t_{i, a}^{F T A}=\underset{t_{i, a}}{\operatorname{argmax}} G_{i}(\mathbf{t}) \\
\text { s.t. } \quad t_{i k, a}=0
\end{gathered}
$$

However as there are no firms producing good a in the partner country the change in the constraint from $t_{i k, a}=t_{i l, a}$ in MFN to $t_{i k, a}=0$ in FTA has no impact on the government objective - in both cases the government only sets the tariff $t_{i l, a}$.

$t^{C U}=\underset{t_{i}, t_{j}}{\operatorname{argmax}} G_{i}(t)+G_{j}(t)$

s.t. $\quad t_{i j}=0, t_{j i}=0, t_{i k}=t_{j k}$

$C S_{i, a}+T R_{i, a}+\Pi_{i i, a}+C S_{j, a}+T R_{j, a}+\Pi_{i j, a}$ because $\Pi_{i i, a}=\Pi_{i j, a}$ and $C S_{i, a}+T R_{i, a}=$ $C S_{j, a}+T R_{j, a}$ by construction

the CU problem is equivalent to $C S_{i, a}+T R_{i, a}+\Pi_{i i, a}$ which is the MFN problem.

ii. The tariff on the only-import good in MFN and FTA is determined by the consumer surplus and tariff revenue considerations. The arguments behind the tariff complementarity make the comparison straightforward. 
The increase in the tariff paid by the rest of the world in the CU compared to the other two trade regimes is presented in part i. It follows that once the country has to match the tariff level to the partner level where the producer interests are being protected, its tariff would be higher than when no producer interests are involved. Indeed, following a similar approach to the symmetric case in derivations, the customs union tariff of the welfare maximising government is:

$$
t^{C U, b}=\frac{\Gamma(2 n+1)}{2 n^{2}+5 n+2}
$$

Meanwhile the MFN tariff in the good that the country does not produce does not depend on the political bias and is:

$$
t^{M F N, b}=\frac{\Gamma}{2(n+1)}
$$

It follows that the difference between $\mathrm{CU}$ and MFN tariff is positive when $\alpha=0$, a difference that will only grow as $\alpha$ increases:

$$
\frac{\Gamma n}{2(n+1)(n+2)}>0
$$

\section{Proof of Proposition 7:}

i. The consumer surplus and tariff revenue in the only-import good in the CU and in the FTA has the following form:

$$
C S_{i, b}+T R_{i, b}=\frac{\left(2 \Gamma n-n t_{i k, b}\right)^{2}}{2(2 n+1)^{2}}+\frac{n t_{i k, b}\left(\Gamma(-n-1) t_{i k, b}\right)}{2 n+1}
$$

While the profits in the partner country have the following form:

$$
\Pi_{i j, a}=n \frac{\left(n t_{j k, a}+\Gamma\right)^{2}}{(2 n+1)^{2}}
$$

Note that as the countries are a mirror image of each other, $t_{i k, b}=t_{j k, a}$

The comparison of the government payoffs in each trade agreement regime leads to the 
following outcome:

$$
G_{i}^{* C U}-G_{i}^{* F T A}=\frac{8(\alpha+1)^{2} \Gamma^{2} n^{3}(n+1)^{2}}{\left(4 n^{2}+5 n+2\right)^{2}\left(2 n^{2}+5 n+2-2 \alpha n^{2}\right)}>0
$$

for all $\alpha<1 /(2 n)$

$$
G_{i}^{* C U}-G_{i}^{* M F N}=\frac{\Gamma^{2} n\left(2 \alpha^{2} n^{2}+4 \alpha n^{2}+2 n^{2}+7 \alpha n+5 n+6 \alpha+4\right)}{4(n+1)^{2}\left(2 n^{2}+5 n+2-2 \alpha n^{2}\right)}>0
$$

ii. The difference in social welfare between CU and FTA is given by:

$$
W_{i}^{* C U}-W_{i}^{* F T A}=\frac{8(\alpha+1) \Gamma^{2} n^{3}(n+1)^{2}\left(2 n^{2}+5 n+2-6 \alpha n^{2}-5 \alpha n-2 \alpha\right)}{\left(4 n^{2}+5 n+2\right)^{2}\left(2 n^{2}+5 n+2-2 \alpha n^{2}\right)^{2}}>0
$$

as at $\alpha=1 /(2 n)$

$$
W_{i}^{* C U}-W_{i}^{* F T A}=\frac{\Gamma^{2} n(2 n+1)\left(4 n^{3}+4 n^{2}-n-2\right)}{2(n+1)^{2}\left(4 n^{2}+5 n+2\right)^{2}}>0
$$

for all $\alpha<1 /(2 n)$

$$
W_{i}^{* C U}-W_{i}^{* M F N}=\frac{\Gamma^{2} n\left(2 \alpha^{2} n^{2}+4 \alpha n^{2}+2 n^{2}+7 \alpha n+5 n+6 \alpha+4\right)}{4(n+1)^{2}\left(2 n^{2}+5 n+2-2 \alpha n^{2}\right)}>0
$$

The welfare advantage of the CU over the MFN follows from the welfare advantage of FTA over MFN.

\section{Acknowledgements}

We thank Luigi Filippini, Piero Gottardi and Natalya Volchkova who followed and supported the paper throughout; seminar audiences at the EUI in Florence, New Economic School in Moscow and Catholic University of Milan, and conference participants at ETSG 2012 in Leuven, RIEF 2012 in Milan and EEA 2013 in Goteburg for their helpful comments. Discussions with Christian Henn, Emanuel Ornelas, Kamal Saggi, David Tarr and Gerald Willmann substantially improved the paper. 
Table 3: Countries Implementing a CU Common External Tariff, by Year

Andean Community

$1992-$

2012 Bolivia, Colombia, Ecuador, Peru

Caribbean Community (CARICOM)

1992

Antigua and Barbuda, Bahamas, Belize, Barbados, Dominica, Grenada, Guyana

Jamaica, Saint Kitts and Nevis, Saint Lucia, Montserrat, Trinidad and Tobago,

Saint Vincent and Grenadines

Antigua and Barbuda, Bahamas, Belize, Barbados, Dominica, Grenada, Guyana

2012 Haiti, Jamaica, Saint Kitts and Nevis, Saint Lucia, Montserrat, Suriname,

Trinidad and Tobago, Saint Vincent and Grenadines

East African Community (EAC)

1992

2012 Burundi, Kenya, Rwanda, Tanzania, Uganda

Eurasian Customs Union

1992

2012 Belarus, Kazakhstan, Russian Federation

European Union Customs Union

1992

Andorra, Belgium, Germany, Denmark, San Marino, Spain, France, United Kingdom, Greece,

Ireland, Italy, Luxembourg, Monaco, Netherlands, Portugal

Andorra, Austria, Belgium, Bulgaria, Cyprus, Czech Republic, Germany, Denmark,

Spain, Estonia, Finland, France, United Kingdom, Greece, Hungary, Ireland, Italy,

Lithuania, Luxembourg, Latvia, Monaco, Malta, Netherlands, Poland, Portugal,

Romania, San Marino, Slovakia, Slovenia, Sweden, Turkey

Gulf Cooperation Council (GCC)

1992

2012 United Arab Emirates, Bahrain, Kuwait, Oman, Qatar, Saudi Arabia

\section{MERCOSUR}

1992

2012 Argentina, Brazil, Paraguay, Uruguay, Venezuela 


\section{References}

Alva, M. AND A. Behar, "Factors that contribute to (or detract from) successful outcomes in African Regional Agreements," (2009).

Bagwell, K. And R. W. Staiger, "Multilateral tariff cooperation during the formation of free trade areas," International Economic Review (1997), 291-319.

BAiER, S. AND J. BERGSTRAND, "Do free trade agreements actually increase members' international trade?," Journal of International Economics 71 (2007), 72-95.

BAKsI, S., "Regional versus Multilateral Trade Liberalization, Environmental Taxation, and Welfare," Canadian Journal of Economics/Revue canadienne d'économique 47 (2014), 232249.

BALdwin, R. AND D. Jaimovich, "Are free trade agreements contagious?," Journal of international Economics 88 (2012), 1-16.

Bohara, A. K., K. Gawande and P. Sanguinetti, "Trade diversion and declining tariffs: evidence from Mercosur," Journal of International Economics 64 (2004), 65-88.

BRANDER, J. AND P. KRUGMAn, "A reciprocal dumping model of international trade," Journal of International Economics 15 (1983), 313-321.

Bronchi, C. and D. Chua, "Trade Liberalization and Tax Coordination," in M. Rodlauer and A. Schipke, eds., Central America: Global Integration and Regional Cooperation (Occasional Paper, 243. International Monetary Fund, 2005).

Bulmer-Thomas, V., "The Central American Common Market: from closed to open regionalism," World Development 26 (1998), 313-322.

Cadot, O., J. De Melo and M. Olarreaga, "Regional integration and lobbying for tariffs against nonmembers," International Economic Review 40 (1999), 635-658. 
Caribbean Community Secretariat, "History of the Caribbean Community (CARICOM)," http://www . caricom.org/jsp/community/history . jsp?menu=community (2015), accessed: 2015-05-18.

CraWford, J.-A. AND R. V. Fiorentino, The changing landscape of regional trade agreements (World Trade Organization, 2005).

Dür, A., L. BACCINI AND M. Elsig, "The design of international trade agreements: Introducing a new dataset," The Review of International Organizations 9 (2014), 353-375.

East African Community Secretariat, "History of the EAC - Milestones in the EAC Integration Process ," http://www.eac.int/index.php?option=com_content\&view=article\& $i d=44 \&$ Itemid=54\&Iimitstart=1 (2015), accessed: 2015-05-18.

Estevadeordal, A., C. Freund and E. Ornelas, "Does regionalism affect trade liberalization toward nonmembers?," The Quarterly Journal of Economics 123 (2008), 1531-1575.

EUR-Lex, "Treaty establishing the European Economic Community, EEC Treaty - original text (non-consolidated version)," http://eur-lex.europa.eu/legal-content/EN/TXT/ ?qid=1432395860399\&uri=URISERV : xy0023 (2015), accessed: 2015-05-18.

Eurasian Economic Union Secretariat, "About the Union: Timeline," http://www. eaeunion.org/?lang=en\#about-history (2015), accessed: 2015-05-18.

European Commission, "Andorra: Customs Unions and preferential arrangements," http://ec.europa.eu/taxation_customs/customs/customs_duties/rules_origin/ customs_unions/article_412_en.htm (2015a), accessed: 2015-05-18.

—, "San Marino : Customs Unions and preferential arrangements," http: //ec.europa.eu/taxation_customs/customs/customs_duties/rules_origin/customs_ unions/article_413_en.htm (2015b), accessed: 2015-05-18.

[, "Turkey : Customs Unions and preferential arrangements," http://ec.europa.eu/ taxation_customs/customs/customs_duties/rules_origin/customs_unions/article_ 414_en.htm (2015c), accessed: 2015-05-18. 
Facchini, G., P. Silva and G. Willmann, "The Customs Union issue: Why do we observe so few of them?," Journal of International Economics 90 (2013), 136-147.

Fasano-Filho, U., Monetary union among member countries of the Gulf Cooperation Council, 223 (International Monetary Fund, 2003).

Fiorentino, R. V., L. Verdeja and C. Toqueboeuf, The changing landscape of regional trade agreements: 2006 update (World Trade Organization, 2007).

Freund, C., "Multilateralism and the endogenous formation of preferential trade agreements," Journal of International Economics 52 (2000), 359-376.

Freund, C. And E. Ornelas, "Regional trade agreements," Annual Review of Economics 2 (2010), 139-166.

Gomez, E., "The Andean Community: economic integration," Technical Report, European Parliamentary Research Service, 2014.

Goretti, M. And H. Weisfeld, "Trade in the WAEMU: Developments and Reform Opportunities," IMF Working Papers (2008), 1-24.

Goyal, S. And S. Joshi, "Bilateralism and Free Trade," International Economic Review 47 (2006), 749-778.

Grossman, G. M. And E. Helpman, "Protection for Sale," American Economie Review 84 (1994), 833-850.

Krishna, P., "Regionalism and Multilateralism: A Political Economy Approach," Quarterly Journal of Economics 113 (1998), 227-250.

Krueger, A. O., "Free trade agreements versus customs unions," Journal of Development Economics 54 (1997), 169-187.

Lake, J., "Why don't more countries form Customs Unions instead of Free Trade Agreements? The role of flexibility," Technical Report, Southern Methodist University, Department of Economics, 2014. 
Lake, J., H. M. Yildiz et AL., "On the different geographic characteristics of Free Trade Agreements and Customs Unions," Technical Report, Southern Methodist University, Department of Economics, 2014.

LaVAllÉE, E. AND V. VicARD, "National borders matter... where one draws the lines too," Canadian Journal of Economics/Revue canadienne d'économique 46 (2013), 135-153.

MageE, S. AND H.-L. LEE, "Endogenous tariff creation and tariff diversion in a customs union," European Economic Review 45 (2001), 495-518.

Maggi, G. And A. Rodriguez-Clare, "The value of trade agreements in the presence of political pressures," Journal of Political Economy 106 (1998), 574-601.

Mavroidis, P. C., "If I don't do it, somebody else will (or won't)," Journal of world trade 40 (2006), 187-214.

— ments, yesterday and today," World Trade Review 10 (2011), 375-387.

McCarthy, C., "The Southern African Customs Union in Transition," African Affairs 102 (2003), 605-630.

Missios, P., K. SAgGi And H. M. Yildiz, "External trade diversion, exclusion incentives and the nature of preferential trade agreements," (2014).

Mkrtchyan, A., "Trade impact of non-tariff trade costs. An Assessment of the Customs Union of Russia, Belarus and Kazakhstan," (2013).

Olarreaga, M. and I. Soloaga, "Endogenous tariff formation: the case of Mercosur," The World Bank Economic Review 12 (1998), 297-320.

ORNElAS, E., "Endogenous free trade agreements and the multilateral trading system," Journal of International Economics 67 (2005a), 471-97.

_ , "Rent destruction and the political viability of free trade agreements," Quarterly Journal of Economics 120 (2005b), 1475-506. 
— "Exchanging market access at the outsiders' expense: the case of customs unions," Canadian Journal of Economic 40 (2007), 207-24.

Richardson, M., "Endogenous protection and trade diversion," Journal of International Economics 34 (1993), 309-324.

Roy, J., "Do Customs Union Members Engage in More Bilateral Trade than Free-Trade Agreement Members?," Review of International Economics 18 (2010), 663-681.

Sadikov, A. M., External Tariff Liberalization in CARICOM: A Commodity-Level Analysis (International Monetary Fund, 2013).

SAGGi, K., "Preferential trade agreements and multilateral tariff cooperation," International Economic Review 47 (2006), 29-58.

Saggi, K., A. Woodland And H. M. Yildiz, "On the Relationship between Preferential and Multilateral Trade Liberalization: The Case of Customs Unions," American Economic Journal. Microeconomics 5 (2013), 63.

SAgGI, K. And H. M. YILdiz, "Bilateralism, multilateralism, and the quest for global free trade," Journal of International Economics 81 (2010), 26-37.

Schотт, J., "The future of the multilateral trading system in a multi-polar world," Regional integration, economic development and global governance, Cheltenham: Elgar (2011), 103-123.

Southern African Customs Union Secretariat, "About SACU: History of SACU," http: //www.sacu. int/about .php?id=394 (2015), accessed: 2015-05-18.

Stoyanov, A., "Tariff evasion and rules of origin violations under the Canada-US Free Trade Agreement," Canadian Journal of Economics/Revue canadienne d'économique 45 (2012), 879-902.

Von Uexkull, E. And L. Shui, "Implementing the ECOWAS Common External Tariff: Challenges and Opportunities for Nigeria," (2014). 
World BANK, "Trading towards prosperity : Sierra Leone diagnostic trade integration study update," http://documents.worldbank.org/curated/en/2015/06/17939550/ trading-towards-prosperity-sierra-leone-diagnostic-trade-integration-study-update (2013).

World Trade Organization, "Trade Policy Review: Switzerland and Liechtenstein," https: //www.wto.org/english/tratop_e/tpr_e/tp150_e.htm (2000), accessed: 2015-05-18. "World Trade Report 2011. WTO and Preferential Trade Agreements: From CoExistence to Coherence," Technical Report, World Trade Organization, 2011.

YI, S.-S., "Endogenous formation of customs unions under imperfect competition: open regionalism is good," Journal of International Economics 41 (1996), 153-177.

Zissimos, B., "Why are trade agreements regional?," Review of International Economics 19 (2011), 32-45. 